\title{
Lead-Zinc Mine Tailings Valorization Through Fly Ash-Based Geopolymer for Building Material: Synthesis, Microstructure, and Mechanical Properties
}

\author{
ALSENY BAH ( $\square$ alsenybah@stu.shmtu.edu.cn ) \\ Shanghai Maritime University https://orcid.org/0000-0002-8613-942X \\ Andrea ORTIZ Ramos \\ Nanjing University of Information Science and Technology \\ Feng Daolun \\ Shanghai Maritime University \\ jie Jin \\ Nanjing University of Information Science and Technology \\ Alhassane Bah \\ Kunming University of Science and Technology

\section{Feihu Li} \\ Nanjing University of Information Science and Technology
}

\section{Research Article}

Keywords: Geopolymer, Solidification, Fly ash, Mine tailing, gypsum, mechanical strength, microstructure.

Posted Date: October 26th, 2021

DOI: https://doi.org/10.21203/rs.3.rs-996321/v1

License: (c) (i) This work is licensed under a Creative Commons Attribution 4.0 International License. Read Full License 


\section{Abstract}

Using geopolymerization to value mining wastes in order to meet construction demand is a sustainable and environmentally friendly strategy. Fly ash geopolymer materials have been developed to address environmental issues such as climate change caused by the emissions of $\mathrm{CO}_{2}$ from coal fly ash plants, mining, and cement industry into the atmosphere. The main objective of this study is to study the feasibility of using mine tailings to produce environmentally friendly building materials (so-called geopolymer products) with excellent mechanical strength through fly-based geopolymer technology. Fly ash (F.A.) and mine tailings (M.T.) were utilized as raw materials and gypsum (G.Y.) as additives. Sodium hydroxide $(\mathrm{NaOH})$ at $(5-10 \mathrm{M})$ and sodium silicate (water glass) constituted the alkaline solution and were added separately to the mixture. The mechanical property and microstructure of the geopolymers were assessed by performing the Unconfined Compressive Strength (UCS), Scanning Electron Microscopy (SEM), X-ray diffractions (XRD), and Fourier transforms infrared (FTIR). A $24 \mathrm{MPa}$ was achieved at $10 \mathrm{M} \mathrm{NaOH}$ with $100 \%$ F.A. Besides, low UCS values were obtained with only M.T. as a binder. The SEM imaging analysis confirmed similar results showing that the geopolymer specimens cured with $100 \%$ of F.A. at $10 \mathrm{M} \mathrm{NaOH}$ with a moderate amount of gypsum are denser than those prepared without gypsum at 5M. The findings revealed that F.A., MT, and gypsum, together with the alkali reagents, influenced the geopolymerisation process. These factors responded effectively to the microstructural performance(increasing density), resulting in increased unconfined compressive strength.

\section{Introduction}

Valorising mine tailings through geopolymerisation to meet construction demand is a sustainable and environmentally friendly approach. Environmental problems have become a worldwide concern. In addition, Heavy metals such as lead $(\mathrm{Pb})$, zinc $(\mathrm{Zn})$, Copper $(\mathrm{Cu})$ are among the most dangerous pollutants which lead to the death of the living organism (Humans, animals) through environmental pollution that occurs by the exploitation of mineral resources. Crushed rocks, as well as effluents from mineral exploration, make up mine tailings. These are the byproducts left over from extracting products from mining ores that have never been a 100 percent effective system; not all agents and chemicals used are recoverable. Mine tailings are also discarded products that provide no economic advantage to the mineral miners at the time of manufacture. Hence they are often kept in the most cost-effective manner possible to meet obligations. (Xiaolong et al. 2021). On the other side, Every year, the issue of long-term dumping of tailings (M.T.) that pile in tailing ponds and mining waste landfills becomes increasingly pressing.(Ngole-Jeme and Fantke 2017; Kinnunen et al. 2018; Krishna et al. 2021). Besides, it occurs as a result of higher manufacturing quantities in mining and metallurgical entities, as well as the absence of meaningful waste-handling techniques. However, also, it is stated, particularly in developed countries, tightening environmental regulations. The continuous inflow of toxic substances, radioactive elements, and other harmful substances into the ecosystem, polluting the soil, is indeed a serious outcome of tailings storage. (W. Zhang et al. 2020), water (Sheoran and Sheoran 2006)and air (Csavina et al. 2012).

The use of M.T. as a major contributor to alkali-activated materials and geopolymers represents an attractive trend for their application. (Kiventerä et al. 2020). This process is an opportunity not just to reduce the dynamics of M.T. accretion and decrease the occurrence of industrial contamination, but it also integrates the benefits of geopolymer technology related to the diminution of carbon dioxide liberation into the atmosphere, the potential for utilizing certain technogenic aluminosilicate waste, and the adaptability of the characteristics of geopolymers as an overall building material (Ma, Awang, and Omar 2018; Hassan, Arif, and Shariq 2019; Lazorenko et al. 2020; Krishna et al. 2021)

Sustainable management of tailings through geopolymers has increasingly attracted the attention of a diverse group of experts, including general practitioners. Numerous research has indeed been reported, highlighting an attempt to improve understanding of the mechanics of tailings geopolymerization to control the characteristics of MT-based geopolymers for long-term development (Moukannaa et al. 2019).

Page 2/25 
Owing to its appealing attributes like superior mechanical properties, enhanced heat resistance, prolonged durability, and reasonable manufacturing costs, geopolymers have indeed been extensively explored as a Portland cement replacement in recent years (Moukannaa et al. 2019)

In order to find sustainable solutions to address these issues, some environment materials such as « Geopolymers » by geopolymerization process that engages chemical reaction of aluminosilicates oxides with Alkali polysilicates yielding polymeric Si-O-Al bonds (Davidovits 1991) and some techniques such as «Solidification / Stabilization technology » have been developed to encapsulate toxic chemical and radioactive waste. In order to diminish the quantity of fly ash from a power plant to be disposed of in the world such as the Czech Republic, the fly ash has to be added to cement and concretes(Škvára, Jílek, and Kopecký 2005; Zhao et al. 2019), in addition, using alkaline solutions reagents such as $\mathrm{NaOH}$, or $\mathrm{Na}_{2} \mathrm{SiO}_{3}$ contribute strongly to geopolymerization process as said (Rattanasak et al. 2011), that geopolymerization happens in alkaline solution, especially in the sodium hydroxide/sodium silicate system.

Gypsum has been utilized in some recent studies to ameliorate the mechanical strength of fly ash-based geopolymers when activating the fly ash by sodium hydroxide $(\mathrm{NaOH})$ and Sodium silicate(Na-silicate) (Jun et al., 2015). CaSO or $^{2}$ gypsum is a suitable additive due to its availability in the market with acceptable cost (Boonserm et al., 2012).

This research, therefore, evaluates the performance of raw materials (Fly Ash (F.A.), Mine Tailings(M.T.), and Gypsum(Gy)) and the Alkali reagents ( $\mathrm{NaOH}$ and Sodium Silicate) to study the mechanical property and microstructure of geopolymers. In order to achieve this research, the XRF, XRD diffractometer, FTIR, SEM imaging, and the Unconfined Compressive Strength (UCS) analysis were performed to investigate the Geopolymer-based solidification of Lead-Zinc mine tailings.

\section{Materials And Methods}

\subsection{Materials}

Based on the availability, affordability, and applicability, the following materials were chosen to conduct this research, including fly ash (F.A.), gypsum (G.Y.), and mine tailings (M.T.), Sodium hydroxide ( $\mathrm{NaOH}$ ), sodium silicate, and distilled water. Both the F.A. and the G.Y. were obtained from Jiangsu Nanre Power Generation Co., Ltd. (Nanjing, China), M.T. was achieved from Nanjing Yinmaoqianxin Mining Industry Co., Ltd. (Nanjing, China). 96\% NaOH pellets were supplied by Shanghai Macklin Biochemical Co., Ltd., and sodium silicate solution ( $\left.\mathrm{SiO}_{2} 13.36 \% ; \mathrm{Na}_{2} \mathrm{O} 29.84 \%\right)$ was obtained from Ganjiashan Yourui Refractories Co., Ltd. Sodium hydroxide and sodium silicate were selected as alkaline agents due to the sodium geopolymers had higher mechanical strength than potassium geopolymers ( Rao et al., 2015). The chemical compositions of both F.A. and M.T. were obtained by the fused X-ray fluorescence (XRF) method, and the results are shown in Tables 1 \&2. The X-ray diffraction (XRD) analysis of the raw materials and geopolymers specimens was performed on an XRD-6100 diffractometer (Shimadzu, Japan), the Fourier Transform Infrared Spectroscopy (FTIR) data were collected on Is 5 infrared spectrometer, and The scanning electron micrograph (SEM) of the raw materials and geopolymers specimens were measured by using a Hitachi japan SU1510 microscope.

\subsection{Synthesis of Geopolymer}

To achieved the objective of this study, forty (40) geopolymer recipes were performed. Samples were prepared by blending the dry reagents about 7 min then gradually adding the alkaline liquid such as $\mathrm{NaOH}$ at $5-10 \mathrm{M}$ and sodium silicate in the different recipes) and further mixing for $5 \mathrm{~min}$. The alkaline solution was prepared by blending the sodium hydroxide solution to de-ionized water (DIW) at $5 \mathrm{M}$ and $10 \mathrm{M}$ with sodium hydroxide flakes and stirring for at least 5 min. Due to the heat generation, adequate time was required for the solution to cool down to room temperature one day before it was used; however, the $\mathrm{NaOH}$ solution and sodium silicate were injected into the dry mixture separately. The samples were 
cast in 20x $20 \times 20 \mathrm{~mm}$ cubes at room temperature for 72 hours before being removed from the molds and kept for another four days at room temperature. Two measurements of the 12 cubes made to measure the compressive strength of 7,14 , and 28 days will be taken. Table (3) presents the mixture design of the different samples performed in the study to find the best recipe to encapsulate the toxic metals, where the labels will represent using letters which are represented by fly ash $(F)$, gypsum $(G)$, mine tailing $(M)$, sodium hydroxide $(S)$, water glass $(W)$. Where W/S expresses the ratio between sodium hydroxide (S) with a water glass or sodium silicate soln (W) were added in some of the mixes. In addition, silica or quartz is the principal impurity in fly ashes. In geopolymerization, silicate is an important activator, so Si / Al ratios higher than 2.5 were commonly investigated in the literature. In this work, the Si / Al ratios of all specimens having in their composition fly ash vary from 1 to 2.54, coinciding with the work of Davidovits and his co-workers, where they concluded that the Si / Al ratio in fly ash-based geopolymers should be between 1 and 3( Rao et al., 2015).

On the other hand, the specimens with a high Si/Al ratio that varies between 10.33 and 12.25 belong to the $100 \%$ of M.T. in the composition. In some works, gypsum applications can reduce porosity; however, an excess amount of gypsum may cause volume instability within the material. As fly ash is an industrial waste material, varying impurities of different chemical substances may be found within fly ash, which resultantly may cause significant changes in reactions; however, gypsum was also added with other ingredients such as calcium silicates and other types of sodium silicates(Jun et al., 2015), that is why in some recipes was added a portion of 10 or 20 grams of the gypsum.

Then the crystallization phase of geopolymers with the highest value of compressive strength

was analyzed through FTIR and XRD machines.

\subsection{Mechanical Property Test}

The unconfined compressive strength (UCS) test is known and utilized to measure geopolymers' solidification effectiveness. It is generally accepted that a UCS of $0.35 \mathrm{MPa}$ (psi) is appropriate for the physical integrity of solidification/ stabilization waste type to withstand standards landfill overburden pressures. (Choi et al., 2009).

$20 \times 20 \times 20 \mathrm{~mm}$ cube specimens were cast for the strength test on mortar at 3, 7, and 28 days UCS. The mortar specimens were cast and cured at $25-30^{\circ} \mathrm{C}$ room temperature. The molds have been covered with protective plastic sheets shortly after casting and de-molded after 24 hours. The compression tests were carried out using a load compression testing machine. At least three samples were tested for every age, as well as the average of the recorded UCS values is being used.

\subsection{Geopolymer Microstructure Analysis}

To understand the geopolymers' properties, physical observation and Methods of mechanical detection were utilized upon selected geopolymers products based on their performance in terms of compressive strength results. FTIR test results were acquired and used an ASTM Standard (IS5 infrared spectrometer) from Thermo Fisher USA and a Shimadzu (Japan) XRD machine model (XRD-6100) with an objective function of (20-60KV and 2-80mA) for the phasing characteristics. Furthermore, morphological properties of geopolymer samples were studied using Hitachi (Japan) SU1510 SEM equipment.

\section{Results And Discussion}

\subsection{Characterization of Fly Ash, Mine Tailing, and Gypsum}

To comprehend the effectiveness of raw resources, including mine tailings, fly ash, and gypsum, in forming a geopolymer, it is necessary to understand their physical and chemical properties, including chemical compositions, mineralogical composition, and size distribution. 
Table 1\&2 shows the chemical composition of fly ash (F.A.) and mine tailings (M.T.) that consisted mostly in a vitreous phase comprising $40.15 \%$ and $35.50 \%$ of $\mathrm{SiO}_{2}$ and $\mathrm{Al}_{2} \mathrm{O}_{3}$, respectively. Also another oxide in lower percentages including $\mathrm{CaO}, \mathrm{Fe}_{2} \mathrm{O}_{3}$, and $\mathrm{MnO}_{2}$ to $8.33 \%, 7.57 \%$, and $0.11 \%$, respectively. The LOI limitations are $8 \%$ and $6 \%$ according to CSA A3001 for Type F fly ash and for Types $\mathrm{Cl}$ and C.H. fly ashes, respectively; considering the acceptable limitations for LOI, the F.A. level is 1.64, allowing the specimen to be utilized for testing and obtaining a great outcome. Heavy metal quantities including $\mathrm{Pb}, \mathrm{Cu}, \mathrm{Y}, \mathrm{Cr}$, and As could also be found in F.A., as shown in Table 2. Fig. 1 shows the XRD patterns of fly ash composition that are utilized in this research. It is clear that the presence of the quartz is $7.9 \%$ and mullite $24.5 \%$, which are the non-reactive crystalline phase, and the amorphous phase present in the F.A. is $67.6 \%$. The distinctive shape of the original fly ash morphology is shown in Fig. 3(a). It appears to be made up of nearly uniform spherical (cenospheres) vitreous fragments with diameters ranging from 2 to $14 \mathrm{~m}$.

Mine tailings mineralogy is largely dependent on the type of the original ore, minerals manufacturing techniques, as well as the level of deterioration during storing in tailings ponds. (Kossoff et al. 2014). Furthermore, The reactivity of prospective geopolymerization precursors is determined by the alkali solubility of silicon and aluminum, determined by their mineralogy. As a result, mine tailings' reactivity can be estimated based on their mineralogical features. (Xu, $H$., van Deventer 2000). Tables $1 \& 2$ display the mine tailings' chemical composition (major oxides and trace elements). It can be seen in these tables that M.T. consist mainly of $\mathrm{Si}, \mathrm{Fe}$, and $\mathrm{Al}$, as shown by the major oxide composition of $18.83 \%$, $29.49 \%, 9.12 \%, 6.20 \%$, and $1.61 \%$ for $\mathrm{SiO}_{2}, \mathrm{CaO}, \mathrm{MnO}_{2}, \mathrm{Fe}_{2} \mathrm{O}_{3}$, and $\mathrm{Al}_{2} \mathrm{O}_{3}$, respectively. The tailings also contain a lower concentration of heavy metal, which could confirm the results of the study " $A$ Research on the Leaching Toxicity of the Solid Waste of a Pb-Zn mine" of Wang et al. (Wang et al. 2015), in which the chemical study revealed that harmful component level in the mine tailings was low, indicating that there was no risk of pollution. As a result, it was determined that mine tailing specimens are not harmful substances. The predominant minerals included in mine tailings, according to XRD examination, are crystalline solids such as sphalerite, gehlenite, gypsum, calcite, brushite, and quartz, (Fig. 1).For the last description of M.T., the bans around $3316 \mathrm{~cm}-1$ were attributed to loosely bound water $(\mathrm{H}-\mathrm{O}-\mathrm{H})$, and the absorption band $1660 \mathrm{~cm}-1$ was induced by $0-\mathrm{H}$ stretching from adsorbed water. The band $1393 \mathrm{~cm}-1$ is associated with symmetric stretching vibration from adsorbed CO2, and the band $1016 \mathrm{~cm}-1$ was assigned to apical Si-O stretching and Si-O-Si stretching. The M.T particle size distribution is shown in Fig. 4; roughly 42.50 percent of both the particulates are less than $60 \mathrm{~m}$, with the remaining 5.56 to $9.41 \mathrm{wt}$ percent having a size ranging from 60 to $200 \mathrm{~m}$. Ultimately, the secondhighest figure in size particle distribution is 13,02 wt percent of particles larger than $200 \mathrm{~m}$. Fig. 3(b,c) also depicts the M.T. amorphous crystals in various sizes. Because mine tailing particulates are angular, dried tailings have a higher strength angle. Since its magnitude is dependent on the mineral processing requirements, it is hard to extrapolate. (Xiaolong et al. 2021).

The description of gypsum was compared with the band standards of the gypsum spectra, the peak around $3396-3562$ $\mathrm{cm}^{-1}$ and $1623 \mathrm{~cm}^{-1}$ own to the $\mathrm{H}-\mathrm{O} * \mathrm{H}$. The S-O, which including the asymmetrical vibration, will be in the band $1139 \mathrm{~cm}-$ 1; the bands 590 to $669 \mathrm{~cm}-1$ represent the asymmetrical deformation vibration. (Wei et al. 2016). The SEM results of the gypsum and the varied forms and structures of both the particulates are shown in Fig. $3(\mathrm{~d})$.

The FTIR spectra of F.A., G.Y., and M.T. are shown in Fig. 2. At first, it will be described the bands of F.A. At $568 \mathrm{~cm}-1$ is due to Al-O-Si symmetric stretching. For Si-O-Si asymmetric stretching is shown in the band at $1066 \mathrm{~cm}$. The structural and geometric knowledge from SEM analysis of crystals helps us define the distinction between raw resources and geopolymers' crystallization.

\subsection{The Physical Characteristic of Geopolymers}

Once the mixtures were done, bulks had different physical characteristics such as color, shape, and integrality. In Fig. 13(a), (b), and (c), different series of geopolymers were shown, whose compositions are described in Table 3; all of them have a cubic shape with a dimension of $20 \times 20 \times 20 \mathrm{~mm}$. 
The specimens labeled with the codes FMS-0x $(x=1,2,3,4$, and 5$)$ have the following characteristics, the colors of these bulks vary from a gray color that little by little changes to a shade of brown by the increase in the amount of mine tailing respectively, the two last specimens of the series FMS-04 and FMS-05 do not conserve the initial cubic shape. The second series with the code FMSW-0x had the same variety of colors with the difference that are a little bit dark, as for its shapes are cubic but with a presence of cracking in the surface of all the series.

Finally, the series FMS-0xa, which were activated with $\mathrm{NaOH}$ at $10 \mathrm{M}$, these series also presented a variety of color but little more intense compared to others, but that is caused by the increase of mine tailing in the mixture, but covered with a white layer that could be due to the interaction of sodium hydroxide with carbon dioxide. By simple observation, it was possible to determine the integrality order of this series of geopolymer specimens as follows:

FMS-01 > FMS-02 > FMS-03 > FMS-04 > FMS-05

FMSW-01 > FMSW -02 > FMSW -03 > FMSW -04 > FMSW -05

FMS-01a $>$ FMS-02a $>$ FMS-03a $>$ FMS-04a $>$ FMS-05a

The specimen's codes FGMS-0x belong to the first line of Fig. 12(a), the colors of these bulks vary from a gray to brown but FGMS-05, was covered with a white layer, cubic shapes with a presence of cracking in the surface of FGMS-03, -04 and -05 , and also observed a light erosion at the corners of the cube in FGMS-05. In the second series with the code FGMS-0xa, the colors of the different bulks presented a grayscale and were observed a slight erosion in the cubic shapes. The integrality order of these series of geopolymer specimens are as follows:

FGMS-01 / FGMS-02 > FGMS-03 > FGMS-04 > FGMS-05

FGMS-01a > FGMS-02a > FGMS-03a > FGMS-04a > FGMS-05a

\subsection{Mechanical Property and Microstructure of Geopolymers 3.3.1 Mechanical Property of Geopolymers}

In order to investigate and figure out the mechanical property of the geopolymer specimens, the effect of the curing time, sodium hydroxide ( $\mathrm{NaOH}$ ), Fly Ash (F.A.), and gypsum (Gy) on the Unconfined Compressive Strength (UCS) were performed based on some selected geopolymers matrix. Furthermore, Table 4 summarizes the samples that have the higher values of UCS of the different series.

\subsubsection{Effect of Curing Time on Mechanical Strength}

The role of curing time on the compressive strength (UCS) has been investigated with the proportion of F.A. (0\%, $25 \%$, $50 \%, 75 \%, 100 \%)$. Fig. 5 shows the result of curing time on the compressive strength for FMS-0xa geopolymer specimens at $10 \mathrm{M} \mathrm{NaOH}$. These mixtures were cured for different curing times, which are 7, 14, and 28 days. Only the FMS-05a mixture with $0 \%$ of F.A. decreased with the increase of curing time. The trends of FMS-04a with $25 \%$ of F.A. which to pass the days will decrease gradually with the increase of curing time but not completely to zero compared to the FMS-05a mixture. that showed the F.A. particles have high reactivity and play a great role in the mechanical properties. The lack of data in compressive strength of the geopolymer specimens with $100 \%$ mine tailing (M.T.) was reported in many research that there is no geopolymerization. Additives like fly ash, gypsum were utilized in geopolymerization processes to consolidate mine tailings (Rao and Liu 2015). 
Figure 5 summarizes the specimens cured at room temperature whose compressive strength values increase with the cured time. A longer curing period increases the polymerization rate resulting in higher compressive strength. The results show that longer curing periods did not lower the compressive strength of geopolymer concrete as declared (Jaarsveld et al. 2002). These will be the best candidates to perform the toxicity study to determine the encapsulation capacity of toxic metals.

\subsubsection{Effect of Fly Ash and $\mathrm{NaOH}$ Concentration on Mechanical Strength}

Figure 12(a-b) displays the result of Unconfined Compressive Strength (UCS) of fly ash-based geopolymer specimens cured at room temperature for seven days with various F.A. proportions $(0 \%, 25 \%, 50 \%, 75 \%, 100 \%)$ and $\mathrm{NaOH}$ concentration at $5 \mathrm{M}$ and $10 \mathrm{M}$. This figure shows that both F.A. and $\mathrm{NaOH}$ contribute strongly to the increase of strength. Higher the amount of F.A. and $\mathrm{NaOH}$ is greater than the UCS value, as demonstrated in another study (Zhang et al. 2011). This is due to higher $\mathrm{O} . \mathrm{H}$. or sodium oxide content during the geopolymerization reaction, as claimed by Zhuang et al. There are reactions and condensation between fly ash and alkaline reagents. The outcome, $\mathrm{Si}^{4+}$, and $\mathrm{Al}^{3+}$, combined with complex crystallization, oligomerization, and polymerization, yields a new aluminosilicate-based polymer with a novel amorphous three-dimensional network structure (Zhuang et al. 2016). The Si/Al ratio played a great role in the geopolymerization as the main precursor. Furthermore, as demonstrated by Zhang et al. (L. Zhang et al., 2011), the elevated of the Unconfined Compressive Strength (UCS) with the proportion of F.A. is owing to the Si/Al ratio of the MT/FA mixture and its reactivity. Generally, a low Si/Al ratio is preferable for a good geopolymerization (Rangan et al., 2014) and should be within 1-3 (Xu et al., 2003; Zhang et al. 2011; Rangan et al., 2014).

\subsubsection{Effect of Gypsum (G) on Mechanical Strength}

In order to investigate the effect of gypsum (G) on the Unconfined Compressive Strength (UCS), three series of geopolymers specimens (FMS-0x, FGMS-0x, and FGMS-0xa) were performed with different proportions of F.A. (0\%, 25\%, $50 \%, 75 \%$, and $100 \%$ ) cured for seven days at $5 \mathrm{M} \mathrm{NaOH}$ with Gypsum that range at $0 \mathrm{~g}, 10 \mathrm{~g}$, and $20 \mathrm{~g}$. Fig. 12 (c) shows the role of gypsum with different proportions of fly ash on the compressive strength. It can be seen that the strength of the geopolymers with gypsum increase compare with those without $\mathrm{G}$, which means adding gypsum can improve the geopolymerization as claimed (Boonserm et al., 2012). The highest peak of strength was gained by adding $10 \mathrm{~g}$ of G. This increase happened because of the entering of $\mathrm{Ca}^{2+}$ in the bond Si-O-Al-O and equilibrating the charge Al ions (FernándezJiménez et al. 2006), that contributes strongly to the formation of $\mathrm{CSH}$, aluminosilicate structure and lead to the improvement of compressive strength (Boonserm et al. 2012). Further, the trend drops down with the increased amount of G (Rattanasak et al., 2011).

\subsubsection{Microstructure and Microchemistry of Geopolymers}

In order to characterize and evaluate the microstructure and microchemistry of fly ash-based-geopolymer matrix and figure out the connection between the microstructure and compressive strength of geopolymers, SEM imaging, XRD diffractometer, and FTIR spectra of selected geopolymers specimens were evaluated.

Finally, it can be noted that one of the most important factors that contribute to the mechanical strength is the water ratio used. Basically, the lower this ratio is, the greater the final UCS strength will be. The geopolymer specimen series (FMS0xa) with 0.27 of Liquid/Solid ratio has recorded the highest values in terms of UCS strength which vary between 1.7 and $14,075 \mathrm{MPa}$. The compressive strength also depends on the curing time. The UCS test of the geopolymer showed slight changes in compressive strength after 28 days, but no changes have been recorded after 56 days(Badur and Chaudhary 2008). When sodium silicate was utilized, the presence of silica retards the zeolite formation rate. As a result, first, greater strength values are gained at lower degrees of reaction. The fly ash activated by an alkaline solution can have a greater compressive strength with greater zeolite content. (Lloyd, 2009) 


\subsubsection{SEM Imaging Analysis}

The SEM imaging was carried out to figure out the effect of aging periods, $\mathrm{NaOH}$ concentration, and gypsum on the microstructure of geopolymers. The SEM micrographs of different geopolymer specimens are displayed in Figs. 7-10.

In order to understand the effect of aging time on the microstructure of the geopolymer specimens, SEM imaging of FGMSW-3b matrix was carried out and cured under room temperature condition after 7, 14, and 28 days with 100\% F.A., $20 \mathrm{~g}$ of $\mathrm{Gy}$ at $10 \mathrm{M}$ of $\mathrm{NaOH}$ concentration (Fig. 7). Fig. 7 provides a comparative analysis of SEM micrographs of various geopolymers effectively treated at varying periods at a moderate optical zoom. According to this figure, there is very little modification in the microstructure of geopolymers after seven days, implying that curing time has little influence on the microstructure, as also stated by another study. (Zhang et al. 2011).

To figure out the effect of sodium hydroxide $(\mathrm{NaOH})$ on the microstructure of geopolymer specimens (FMS-02 and FMS02a) cured under room temperature after 14 days curing period with $100 \%$ F.A. at different concentrations of $\mathrm{NaOH}$ ( $5 \mathrm{M}$ and 10M), the SEM imaging was investigated. Fig. 8 depicts the various modifications shown in the micro-structural of the geopolymers. Fig. 8 (a) showed the existence of F.A. in a negligible amount as the concentration of $\mathrm{NaOH}$ increases, discussing the function of $\mathrm{NaOH}$ in polymerization. Fig. 8 (b) indicates the existence of F.A. in a massive portion as the concentration of $\mathrm{NaOH}$ increases, which also clarifies the function of $\mathrm{NaOH}$ in geopolymers. Further analysis revealed that at $15 \mathrm{M} \mathrm{NaOH}$, the particles of F.A. have been almost non-existent, indicating that the increased the $\mathrm{NaOH}$ concentration, the faster the geopolymerization rate. At 15M, the geopolymer gel was much more cohesive and thicker than that at 5 and 10M, yet geopolymerization was quite substantial at 10M (Zhang et al. 2011). It also confirms the compressive strength (UCS) results (Fig. 12 (a)), which show that the maximum UCS value was acquired to $10 \mathrm{M} \mathrm{NaOH}$.

The effect of sodium silicate (Na-silicate) on the microstructure was evaluated, by comparing the specimen FMS-01 activated with only $\mathrm{NaOH}$ and FMSW- 01 activated with $\mathrm{NaOH}$ and $\mathrm{Na}$-silicate both cured at ambient temperature, at $5 \mathrm{M}$ $\mathrm{NaOH}$ with $100 \%$ F.AAs shown in Fig. 9 (c) and (d), there is still a notable change in structural system between all these images; Fig. 9 (d) is more compact than Fig. 9 (c), attributed to the existence of sodium silicate in that sample at a 1.08:1 ratio. Once sodium hydroxide $(\mathrm{NaOH})$ and sodium silicate (Na-Silicate) are mixed to make an alkali solution, the blending has superior mechanical properties than $\mathrm{NaOH}$ alone(Palomo et al. 1999); the very same research claimed that sample only with $\mathrm{NaOH}$ has a porous material compared to one provided both with $\mathrm{NaOH}$ and $\mathrm{Na}$-Silicate, which has a higher density structure.

To understand the effect of gypsum on the microstructure of the geopolymer matrixes (FMS-02, FGMS-02, and FGMS02a) at low magnification, the SEM analysis was performed with 75\% F.A. at 5M NaOH at different content of gypsum: (a) $0 \mathrm{~g}$, (b) and (c) $20 \mathrm{~g} 10 \mathrm{~g}$ of gypsum cured for seven days curing under ambient air condition. The scanning electron microscopy (SEM) geopolymer matrixes (FMS-02, FGMS-02, and FGMS-02a) are displayed in Fig. 10. This figure reveals that the opacity of these three geopolymers varies significantly. The sample of FGMS-02 with $10 \mathrm{~g}$ of Gy in Fig. 10 (b) is much more condensed with low permeability than that of the other geopolymers; nevertheless, there is much more unreacted F.A. in the FMS-02 geopolymer with $0 \mathrm{~g}$ of Gy in Fig. 10 (a) than the other geopolymers, which clarified the function which gypsum performed in terms of microstructures and mechanical properties by boosting the polymerization rate. In addition, these SEM imaging results justified the Unconfined Compressive Strength results (Fig. 12. (c)) that the UCS values increased with the addition of $10 \mathrm{~g}$ of $\mathrm{Gy}$. This performance could be attributed to the combination of mine tailings (low reactivity) to fly ash (high reactivity) and gypsum, which concurred with the research finding of Xiaolong et al., which claimed that mine tailings are often crystalline, leading to low reactivity throughout geopolymerization therefore; as a result, products with minimal compressive performance. As a result, adding extra elements with higher reactivity to mine tailings-based geopolymers can efficiently tune and optimize their characteristics. (Xiaolong et al. 2021). Furthermore, because most of the chemicals included in this function are manufacturing wastes, its use has 
additional benefits for the environment. Strong-containing calcium compounds have such a higher favorable impact on geopolymer durability than lower-containing calcium. This is due to the development of extra CSH gels, which, when combined with NASH, increases structural integrity, as previously reported by Xiaolong et al.,.(Xiaolong et al. 2021)

\subsubsection{XRD Analysis}

X-ray fluorescence spectrometry has been used to determine the elemental composition of the geopolymers using the XRD-6100 diffractometer and the XRD patterns have been analysed through JADE 6.0 Software. Because of its amorphous or nanocrystalline nature, the N-A-S-H gel formed during polymerization is difficult to characterize with XRD. Nonetheless, the XRD patterns of the specimens were used to determine the crystalline formation in the different mixture designs of the fly ash-based geopolymer presented with high compressive strength. (FMS-01a (100\% F.A.), FGMS-02 (75\% F.A.), FGMSW-02 (75\% F.A.), FGMSW-01a (100\% F.A.), FGMSW-03b (50\% F.A.), synthesized under room temperature conditions cured at 7, 14 and 28 days is shown in Fig. 6, where different phases have been obtained. Where $\mathrm{C}=\mathrm{Corundum}$ $\mathrm{Al}_{2} \mathrm{O}_{3}, \mathrm{Cc}=$ Calcite $\mathrm{CaCO}_{3}, \mathrm{G}=$ Gypsum CaSO ${ }_{4} 2 \mathrm{H}_{2} \mathrm{O}, \mathrm{M}=$ Mullite $\mathrm{Al}_{6} \mathrm{Si}_{2} \mathrm{O}_{13}, \mathrm{Q}=$ quartz $\mathrm{SiO}_{2}$, Ss=Sodium silicate $\mathrm{Na}_{2}\left(\mathrm{SiO}_{3}\right)$, $\mathrm{Sh}=$ Calcium Silicate hydritade $\mathrm{Ca}_{1} .5 \mathrm{Si}_{0.5} \times \mathrm{H}_{2} \mathrm{O}, \mathrm{Ch}=$ Chabazite, $\mathrm{J}=$ Jadeite, $\mathrm{A}=$ Anhydrite $\mathrm{CaSO}_{4}$.

Mullite and quartz, which have been discovered in raw fly ash, were observed throughout all samples. All of the enabled samples exhibited amorphous ridges focused around $220^{\circ}$ to $30^{\circ}$, including all samples, confirmed the formation of a geopolymer gel. (Keyte et al., 2009a). Except for the FMSW-05 sample, that does not show the geopolymerization since mine tailing is the only element in its composition. Singh et al., in their research, found a similar observation (Singh et al., 2018). Numerous crystalline structures, including quartz and mullite, have been regarded as non-reactive, even though their reaction speed in alkali-silicate solutions is remarkably slower when compared to inorganic materials.(Keyte et al., 2009b) in some of the samples as FGMS-02 and FGMSW-03, could identify de chabazite, which is one of the crystal that can encapsulate the heavy metals such as $\mathrm{Cu}$ and $\mathrm{Pb}$ (Jun et al., 2015).

Calcite, $\mathrm{CaCO} 3$, is formed once calcium hydroxide reacts to carbon dioxide in the atmosphere; calcium solubility at elevated pHs has been well recognized to decrease due to the instability of calcium hydroxide forming(Komnitsas and Zaharaki 2009), his mineral was found in the majority of the samples.

Crystallization amorphous gels were the subtler shown in fly ash-derived geopolymers. Compared to the fly ash instance, much less of the binder is gradually morphed into zeolite stages. Furthermore, variables that promote zeolite forming, like increasing the alkalis of the binder, increasing strength, and reducing any proclivity for strength loss, at least for the duration considered. The creation of zeolites, including chabazite, was recognized through XRD analysis in most specimens. Other minerals discovered included calcite and quartz, which were linked to the presence of zeolites.

\subsubsection{FTIR Analysis}

The FTIR of the five best specimens in terms of compressive strength with various materials was investigated. The FTIR spectra of the five (5) geopolymers (FMS-01a (100\% F.A.), FGMS-02a (75\% F.A.), FGMSW-02(75\% F.A.), FGMSW-02(75\% F.A.), and FGMSW-03b (50\% F.A.), containing a different proportion of Fly Ash and sodium hydroxide concentration (5M, $10 \mathrm{M})$ cured at 7, 14 and 28 days are shown in Fig. 11. Table 5 shows the Infrared characteristic bands identified in F.A. and geopolymers specimens. In-plane and bending vibrations of Al-O / Si-O, 460 $\mathrm{cm}^{-1}$, and $550 \mathrm{~cm}-1$ are assigned. The existence of a $1456 \mathrm{~cm}-1$ band may be due to $\mathrm{C}=0$ vibrations, which indicate the presence of carbonate bands. In addition, the I.R. spectra studies show bands close to $1016 \mathrm{~cm}-1$ and $1143 \mathrm{~cm}-1$ due to asymmetric Si-0 stretching while banding at $458 \mathrm{~cm}-1$ to SiO4 bending in-plane Si-O. However, bands between 772, 579, 537, and $439 \mathrm{~cm}-1 \mathrm{correlate}$ with Al-Si minerals. In addition, new bands emerging at 3423, 1638, and $1540 \mathrm{~cm}-1$ are consistent with-OH, $\mathrm{H}_{2} \mathrm{O}$ bending and asymmetric carbonate stretching, respectively (Ismaiel Saraya and El-Fadaly 2017). The peak appeared at $1640 \mathrm{~cm}-1$ as a result of bending $\mathrm{H}-\mathrm{O}-\mathrm{H}$ vibration, and the intensity of this peak increased with a rise in $\mathrm{NaOH}$ concentration, suggesting a rise in geopolymerization degree (Devi and Saroha 2016). 


\section{Conclusions}

From this study, it can be concluded that fly ash, mine tailings with gypsum as an additive by using Sodium hydroxide $(\mathrm{NaOH})$ at (5-10M) and sodium silicate (water glass) as the alkali reagents can be used to study the feasibility of geopolymerization. In this work, eight geopolymer recipes were made based on fly ash. Both F.A. and M.T. were added in different proportions $(0,25,50,75$, and $100 \%)$ of the total weight. The different dosages mentioned in the design section of the geopolymers gave rise to 40 recipes of geopolymers, which after being mixed and cured at room temperature after 7,14 , and 14 days curing time, showed slight physical changes compared to those without F.A. content could not maintain their shape and hardness. Furthermore, From this research, we remark that mine tailings could not be used alone in performing geopolymer products owing to their low reactivity. However, associating mine tailings with other binders with high reactivity, such as fly ash or high content in $\mathrm{SiO}_{2}$, would make mine tailings a suitable binder in geopolymerisation. In summary, the Unconfined Compressive Strength (UCS) of Geopolymers, the mechanical properties, and microstructure were influenced by curing time, temperature, and the chemical reactions. Furthermore, this study demonstrated that mine tailings could be successfully valorized through geopolymerization to generate eco-friendly products that would sustainably use in the building and construction materials industry.

\section{Declarations}

\section{Acknowledgments}

The work was supported by the Postgraduate Research \& Practice Innovation Program of Jiangsu Province (SJCX170261), NSFC (51002080, 41501197), SPITP (201610300273), Top-notch Academic Programs Project of Jiangsu Higher Education Institutions (PPZY2015C222), and the Priority Academic Program Development of Jiangsu Higher Education Institutions (PAPD).

Conflicts of interest/Competing interests The authors declare that they have no known competing financial interests or personal relationships that could have appeared to influence the work reported in this paper.

Funding (no)

Availability of data and material (all data are included within the manuscript)

Code availability (no)

\section{Consent for publication "Not applicable"}

\section{References}

1. Badur, Smita, and Rubina Chaudhary. 2008. "Utilization of Hazardous Wastes and By-Products as a Green Concrete Material through S/S Process: A Review." Reviews on Advanced Materials Science 17 (1-2): 42-61.

2. Boonserm, Kornkanok, Vanchai Sata, Kedsarin Pimraksa, and Prinya Chindaprasirt. 2012. "Microstructure and Strength of Blended FBC-PCC Fly Ash Geopolymer Containing Gypsum as an Additive." ScienceAsia 38 (2): 175-81. https://doi.org/10.2306/scienceasia1513-1874.2012.38.175.

3. Choi, W. H., S. R. Lee, and J. Y. Park. 2009. "Cement Based Solidification/Stabilization of Arsenic-Contaminated Mine Tailings." Waste Management 29 (5): 1766-71. https://doi.org/10.1016/j.wasman.2008.11.008.

4. Csavina, Janae, Jason Field, Mark P. Taylor, Song Gao, Andrea Landázuri, Eric A. Betterton, and A. Eduardo Sáez. 2012. "A Review on the Importance of Metals and Metalloids in Atmospheric Dust and Aerosol from Mining 
Operations." Science of the Total Environment 433 (September): 58-73.

https://doi.org/10.1016/j.scitotenv.2012.06.013.

5. Davidovits, J. 1991. “Geopolymers - Inorganic Polymeric New Materials.” Journal of Thermal Analysis 37 (8): $1633-$ 56. https://doi.org/10.1007/BF01912193.

6. Devi, Parmila, and Anil K. Saroha. 2016. "Risk Assessment and Technical Feasibility of Usage of Paper Mill Sludge Biochar-Based Exhausted Adsorbent for Geopolymeric Brick Formation." Environmental Science and Pollution Research 23 (21): 21641-51. https://doi.org/10.1007/s11356-016-7343-4.

7. Fernández-Jiménez, A., A. Palomo, I. Sobrados, and J. Sanz. 2006. "The Role Played by the Reactive Alumina Content in the Alkaline Activation of Fly Ashes." Microporous and Mesoporous Materials 91 (1-3): 111-19. https://doi.org/10.1016/j.micromeso.2005.11.015.

8. Hassan, Amer, Mohammed Arif, and M. Shariq. 2019. "Use of Geopolymer Concrete for a Cleaner and Sustainable Environment - A Review of Mechanical Properties and Microstructure." Journal of Cleaner Production 223 (June): 704-28. https://doi.org/10.1016/j.jclepro.2019.03.051.

9. Ismaiel Saraya, Mohamed El-Shahte, and Ezzat El-Fadaly. 2017. "Preliminary Study of Alkali Activation of Basalt: Effect of $\mathrm{NaOH}$ Concentration on Geopolymerization of Basalt." Journal of Materials Science and Chemical Engineering 05 (11): 58-76. https://doi.org/10.4236/msce.2017.511006.

10. Jaarsveld, J G S Van, J S J Van Deventer, and G C Lukey. 2002. "<Vanjaarsveld2002.Pdf>." Chemical Engineering Journal 89: 63-73.

11. Jun, Yubin, and Jae Eun Oh. 2015. "Use of Gypsum as a Preventive Measure for Strength Deterioration during Curing in Class F Fly Ash Geopolymer System." Materials 8 (6): 3053-67. https://doi.org/10.3390/ma8063053.

12. Keyte, L. M. 2009a. Fly Ash Glass Chemistry and Inorganic Polymer Cements. Geopolymers: Structures, Processing, Properties and Industrial Applications. Woodhead Publishing Limited. https://doi.org/10.1533/9781845696382.1.15.

13. Keyte, L.M. 2009b. “Fly Ash Glass Chemistry and Inorganic Polymer Cements.” In Geopolymers, 15-36. Elsevier. https://doi.org/10.1533/9781845696382.1.15.

14. Kinnunen, Paivo, Arnold Ismailov, Soili Solismaa, Harisankar Sreenivasan, Marja Liisa Räisänen, Erkki Levänen, and Mirja Illikainen. 2018. "Recycling Mine Tailings in Chemically Bonded Ceramics - A Review." Journal of Cleaner Production 174 (February): 634-49. https://doi.org/10.1016/j.jclepro.2017.10.280.

15. Kiventerä, Jenni, Priyadharshini Perumal, Juho Yliniemi, and Mirja Illikainen. 2020. "Mine Tailings as a Raw Material in Alkali Activation: A Review." International Journal of Minerals, Metallurgy and Materials 27 (8): 1009-20. https://doi.org/10.1007/s12613-020-2129-6.

16. Komnitsas, K., and D. Zaharaki. 2009. "Utilisation of Low-Calcium Slags to Improve the Strength and Durability of Geopolymers." In Geopolymers, 343-75. Elsevier. https://doi.org/10.1533/9781845696382.2.343.

17. Kossoff, D., W.E. Dubbin, M. Alfredsson, S.J. Edwards, M.G. Macklin, and K.A. Hudson-Edwards. 2014. "Mine Tailings Dams: Characteristics, Failure, Environmental Impacts, and Remediation." Applied Geochemistry 51 (December): 229-45. https://doi.org/10.1016/j.apgeochem.2014.09.010.

18. Krishna, R. S., Faiz Shaikh, Jyotirmoy Mishra, Georgy Lazorenko, and Anton Kasprzhitskii. 2021. "Mine TailingsBased Geopolymers: Properties, Applications and Industrial Prospects." Ceramics International 47 (13): 17826-43. https://doi.org/10.1016/j.ceramint.2021.03.180.

19. Lazorenko, Georgy, Anton Kasprzhitskii, Alexander Kruglikov, Vasilii Mischinenko, and Victor Yavna. 2020. "Sustainable Geopolymer Composites Reinforced with Flax Tows." Ceramics International 46 (8): 12870-75. https://doi.org/10.1016/j.ceramint.2020.01.184.

20. Lloyd, R.R. 2009. "Accelerated Ageing of Geopolymers." In Geopolymers, 139-66. Elsevier. https://doi.org/10.1533/9781845696382.2.139.

Page $11 / 25$ 
21. Ma, Chau Khun, Abdullah Zawawi Awang, and Wahid Omar. 2018. "Structural and Material Performance of Geopolymer Concrete: A Review." Construction and Building Materials 186 (October): 90-102. https://doi.org/10.1016/j.conbuildmat.2018.07.111.

22. Moukannaa, S., A. Nazari, A. Bagheri, M. Loutou, J. G. Sanjayan, and R. Hakkou. 2019. "Alkaline Fused Phosphate Mine Tailings for Geopolymer Mortar Synthesis: Thermal Stability, Mechanical and Microstructural Properties." Journal of Non-Crystalline Solids 511 (May): 76-85. https://doi.org/10.1016/j.jnoncrysol.2018.12.031.

23. Ngole-Jeme, Veronica Mpode, and Peter Fantke. 2017. “Ecological and Human Health Risks Associated with Abandoned Gold Mine Tailings Contaminated Soil." Edited by Jorge Paz-Ferreiro. PLoS ONE 12 (2): e0172517. https://doi.org/10.1371/journal.pone.0172517.

24. Palomo, A., M. W. Grutzeck, and M. T. Blanco. 1999. "Alkali-Activated Fly Ashes: A Cement for the Future." Cement and Concrete Research 29 (8): 1323-29. https://doi.org/10.1016/S0008-8846(98)00243-9.

25. Rangan, B. Vijaya. 2014. “Geopolymer Concrete for Environmental Protection.” Indian Concrete Journal 88 (4): 41 59.

26. Rao, Feng, and Qi Liu. 2015. "Geopolymerization and Its Potential Application in Mine Tailings Consolidation: A Review.” Mineral Processing and Extractive Metallurgy Review 36 (6): 399-409.

https://doi.org/10.1080/08827508.2015.1055625.

27. Rattanasak, Ubolluk, Kanokwan Pankhet, and Prinya Chindaprasirt. 2011. "Effect of Chemical Admixtures on Properties of High-Calcium Fly Ash Geopolymer." International Journal of Minerals, Metallurgy and Materials 18 (3): 364-69. https://doi.org/10.1007/s12613-011-0448-3.

28. Sheoran, A. S., and V. Sheoran. 2006. "Heavy Metal Removal Mechanism of Acid Mine Drainage in Wetlands: A Critical Review." Minerals Engineering 19 (2): 105-16. https://doi.org/10.1016/j.mineng.2005.08.006.

29. Singh, Nakshatra. 2018. “Fly Ash-Based Geopolymer Binder: A Future Construction Material.” Minerals 8 (7): 299. https://doi.org/10.3390/min8070299.

30. Škvára, František, Tomás Jílek, and Lubomír Kopecký. 2005. “Geopolymer Materials Based on Fly Ash.” Ceramics Silikaty 49 (3): 195-204.

31. Wang, Shun-Cai, Zhi-cheng Wei, Yan Zhou, and Fang-Han Wang. 2015. "A Research on the Leaching Toxicity of the Solid Waste of a Pb-Zn Mine." Journal of Residuals Science \& Technology 12 (1): 25-30. https://doi.org/10.12783/issn.2376-578X/12/1/4.

32. Wei, Yan, Liao Jun-Cheng, Wang Shu-Mei, Liang Sheng-Wang, and Yu Jiang-Yong. 2016. "The Ftir Fingerprint of Gypsum Fibrosum." Acta Medica Mediterranea 32 (Speciallssue1): 607-11.

33. Xiaolong, Zhang, Zhang Shiyu, Liu Hui, and Zhao Yingliang. 2021. “Disposal of Mine Tailings via Geopolymerization.” Journal of Cleaner Production 284 (xxxx): 124756.

https://doi.org/10.1016/j.jclepro.2020.124756.

34. Xu, H., van Deventer, J. 2000. "The Geopolymerisation of Alumino-Silicate Minerals." Int. J. Miner. Process. 59: 24766.

35. Xu, Hua, and Jannie S.J. Van Deventer. 2003. “Effect of Source Materials on Geopolymerization." Industrial and Engineering Chemistry Research 42 (8): 1698-1706. https://doi.org/10.1021/ie0206958.

36. Zhang, Lianyang, Saeed Ahmari, and Jinhong Zhang. 2011. "Synthesis and Characterization of Fly Ash Modified Mine Tailings-Based Geopolymers." Construction and Building Materials 25 (9): 3773-81. https://doi.org/10.1016/j.conbuildmat.2011.04.005.

37. Zhang, Wei, Jinghua Long, Xueru Zhang, Weining Shen, and Zhongyi Wei. 2020. "Pollution and Ecological Risk Evaluation of Heavy Metals in the Soil and Sediment around the HTM Tailings Pond, Northeastern China." 
International Journal of Environmental Research and Public Health 17 (19): 1-10.

https://doi.org/10.3390/ijerph17197072.

38. Zhao, Shujie, Faheem Muhammad, Lin Yu, Ming Xia, Xiao Huang, Binquan Jiao, Ning Lu, and Dongwei Li. 2019. "Solidification/Stabilization of Municipal Solid Waste Incineration Fly Ash Using Uncalcined Coal Gangue-Based Alkali-Activated Cementitious Materials." Environmental Science and Pollution Research 26 (25): 25609-20. https://doi.org/10.1007/s11356-019-05832-5.

39. Zhuang, Xiao Yu, Liang Chen, Sridhar Komarneni, Chun Hui Zhou, Dong Shen Tong, Hui Min Yang, Wei Hua Yu, and Hao Wang. 2016. "Fly Ash-Based Geopolymer: Clean Production, Properties and Applications." Journal of Cleaner Production 125 (July): 253-67. https://doi.org/10.1016/j.jclepro.2016.03.019.

\section{Tables}

Table.1 Chemical Compositions of class $\mathrm{F}$ fly ash and Lead-Zinc mine tailing

\begin{tabular}{|c|c|c|c|c|c|c|c|c|c|c|c|c|}
\hline & \multicolumn{12}{|c|}{ Element (wt \%) } \\
\hline & $\mathrm{SiO}_{2}$ & $\mathrm{Al}_{2} \mathrm{O}_{3}$ & $\mathrm{Fe}_{2} \mathrm{O}_{3}$ & $\mathrm{MnO}_{2}$ & $\mathrm{CaO}$ & $\mathrm{MgO}$ & $\mathrm{K}_{2} \mathrm{O}$ & $\mathrm{Na}_{2} \mathrm{O}$ & $\mathrm{P}_{2} \mathrm{O}_{5}$ & $\mathrm{TiO}_{2}$ & $\mathrm{SO}_{3}$ & LOI \\
\hline FA & 40.15 & 35.50 & 7.57 & 0.11 & 8.33 & 1.21 & 1.48 & 1.10 & 0.37 & 1.51 & 0.70 & 1.64 \\
\hline MT & 18.83 & 1.61 & 6.20 & 9.12 & 29.49 & 2.83 & 0.15 & 0.12 & 0.03 & 0.06 & 2.30 & 28.96 \\
\hline
\end{tabular}

Table.2 Chemical Composition of FA and MT - Minor and Trace Elements (ppm)

\begin{tabular}{|c|c|c|c|c|c|c|c|c|c|c|c|c|c|c|}
\hline & \multicolumn{14}{|c|}{ Element (ppm) } \\
\hline & As & Mo & $\mathrm{Pb}$ & $\mathrm{Rb}$ & Th & $U$ & Y & $\mathrm{Zr}$ & $\mathrm{Ga}$ & $\mathrm{Cu}$ & Co & $\mathrm{Ni}$ & $\mathrm{Cr}$ & V \\
\hline FA & 21.3 & 14.4 & 101.4 & 47.2 & 32.3 & 12.5 & 64.5 & 433.8 & 67.4 & 75.1 & 25.4 & 45.5 & 61.7 & 182.1 \\
\hline MT & 151.9 & 0.7 & 622.4 & 10.6 & 11.5 & 7.5 & 63.6 & 28.7 & 26.6 & 52.9 & 1.4 & 10.1 & 24.3 & 97 \\
\hline
\end{tabular}

Table.3 Mixture Design for Geopolymerization of Mine Tailings 


\begin{tabular}{|c|c|c|c|c|c|c|c|c|}
\hline \multirow[t]{2}{*}{$\mathrm{S}(\mathrm{NaOH})$} & \multirow[t]{2}{*}{ Specimen Code } & \multicolumn{3}{|c|}{ Waste materials (g) } & \multicolumn{4}{|l|}{ Ratios } \\
\hline & & $\mathbf{F}$ & G & M & $\mathrm{Si} / \mathrm{Al}$ & $\mathrm{Na} / \mathrm{Al}$ & Liquid/Solid & W/S \\
\hline \multirow[t]{5}{*}{$5 \mathrm{M}$} & FMS-01 & 200 & - & 0 & 1.13 & 0.14 & 0.27 & - \\
\hline & FMS-02 & 150 & - & 50 & 1.29 & 0.18 & 0.27 & - \\
\hline & FMS-03 & 100 & - & 100 & 1.59 & 0.25 & 0.27 & - \\
\hline & FMS-04 & 50 & - & 150 & 2.39 & 0.43 & 0.27 & - \\
\hline & FMS-05 & 0 & - & 200 & 11.71 & 2.57 & 0.27 & - \\
\hline \multirow[t]{5}{*}{$10 M$} & FMS-01a & 200 & - & 0 & 1.13 & 0.26 & 0.27 & - \\
\hline & FMS-02a & 150 & - & 50 & 1.29 & 0.33 & 0.27 & - \\
\hline & FMS-03a & 100 & - & 100 & 1.59 & 0.47 & 0.27 & - \\
\hline & FMS-04a & 50 & - & 150 & 2.39 & 0.83 & 0.27 & - \\
\hline & FMS-05a & 0 & - & 200 & 11.71 & 5.07 & 0.27 & - \\
\hline \multirow[t]{5}{*}{$5 \mathrm{M}$} & FMSW-01 & 200 & - & 0 & 1.13 & 0.14 & 0.52 & 1.08:1 \\
\hline & FMSW-02 & 150 & - & 50 & 1.29 & 0.18 & 0.52 & 1.08:1 \\
\hline & FMSW-03 & 100 & - & 100 & 1.59 & 0.25 & 0.52 & 1.08:1 \\
\hline & FMSW-04 & 50 & - & 150 & 2.39 & 0.43 & 0.52 & 1.08:1 \\
\hline & FMSW-05 & 0 & - & 200 & 11.71 & 2.57 & 0.52 & 1.08:1 \\
\hline \multirow[t]{5}{*}{$5 \mathrm{M}$} & FGMS-01 & 200 & 10 & 0 & 1.13 & 0.14 & 0.32 & - \\
\hline & FGMS-02 & 150 & 10 & 50 & 1.29 & 0.18 & 0.32 & - \\
\hline & FGMS-03 & 100 & 10 & 100 & 1.59 & 0.25 & 0.32 & - \\
\hline & FGMS-04 & 50 & 10 & 150 & 2.39 & 0.43 & 0.32 & - \\
\hline & FGMS-05 & 0 & 10 & 200 & 11.71 & 2.57 & 0.32 & - \\
\hline \multirow[t]{5}{*}{$5 \mathrm{M}$} & FGMS-01a & 200 & 20 & 0 & 1.13 & 0.14 & 0.37 & - \\
\hline & FGMS-02a & 150 & 20 & 50 & 1.29 & 0.18 & 0.37 & - \\
\hline & FGMS-03a & 100 & 20 & 100 & 1.59 & 0.25 & 0.37 & - \\
\hline & FGMS-04a & 50 & 20 & 150 & 2.39 & 0.43 & 0.37 & - \\
\hline & FGMS-05a & 0 & 20 & 200 & 11.71 & 2.57 & 0.37 & - \\
\hline \multirow[t]{5}{*}{$5 \mathrm{M}$} & FGMSW-01 & 200 & 10 & 0 & 1.23 & 2.95 & 0.57 & 1.08:1 \\
\hline & FGMSW-02 & 150 & 10 & 50 & 1.41 & 3.87 & 0.57 & $1.08: 1$ \\
\hline & FGMSW-03 & 100 & 10 & 100 & 1.77 & 5.62 & 0.57 & 1.08:1 \\
\hline & FGMSW-04 & 50 & 10 & 150 & 2.73 & 10.32 & 0.57 & 1.08:1 \\
\hline & FGMSW-05 & 0 & 10 & 200 & 13.79 & 64.55 & 0.57 & 1.08:1 \\
\hline \multirow[t]{2}{*}{$5 \mathrm{M}$} & FGMSW-01a & 200 & 20 & 0 & 1.23 & 2.95 & 0.62 & 1.08:1 \\
\hline & FGMSW-02a & 150 & 20 & 50 & 1.41 & 3.87 & 0.62 & $1.08: 1$ \\
\hline
\end{tabular}




\begin{tabular}{|c|c|c|c|c|c|c|c|c|}
\hline & FGMSW-03a & 100 & 20 & 100 & 1.77 & 5.62 & 0.62 & $1.08: 1$ \\
\hline & FGMSW-04a & 50 & 20 & 150 & 2.73 & 10.32 & 0.62 & $1.08: 1$ \\
\hline & FGMSW-05a & 0 & 20 & 200 & 13.79 & 64.55 & 0.62 & $1.08: 1$ \\
\hline \multirow[t]{5}{*}{$10 \mathrm{M}$} & FGMSW-01b & 200 & 20 & 0 & 1.23 & 3.07 & 0.62 & $1.08: 1$ \\
\hline & FGMSW-02b & 150 & 20 & 50 & 1.41 & 4.02 & 0.62 & $1.08: 1$ \\
\hline & FGMSW-03b & 100 & 20 & 100 & 1.77 & 5.84 & 0.62 & $1.08: 1$ \\
\hline & FGMSW-04b & 50 & 20 & 150 & 2.73 & 10.72 & 0.62 & $1.08: 1$ \\
\hline & FGMSW-05b & 0 & 20 & 200 & 13.79 & 67.05056 & 0.62 & $1.08: 1$ \\
\hline
\end{tabular}

Table 4. Table of the samples that have the higher values of UCS of the different series.

\begin{tabular}{|c|c|c|c|c|c|c|c|}
\hline \multicolumn{2}{|c|}{$\begin{array}{l}\text { Alkali activator } \\
\text { content }\end{array}$} & $\begin{array}{l}\text { MT content/ } \\
\text { other } \\
\text { aggregates }\end{array}$ & $0 \%$ & $25 \%$ & $50 \%$ & $75 \%$ & $100 \%$ \\
\hline $\mathrm{NaOH}$ & $5 \mathrm{M}$ & & & & FMS-03a & FMS-04 & \\
\hline $\mathrm{NaOH}$ & $10 \mathrm{M}$ & & FMS-01a & FMS-02a & FMS-03 & FMS-04a & \\
\hline WG/ & $2 \mathrm{~N} /$ & & FMSW-01 & FMSW-02 & FMSW-03 & FMSW-04 & FMSW-05 \\
\hline $\mathrm{NaOH}$ & $5 \mathrm{M}$ & & & & & & \\
\hline $\mathrm{NaOH}$ & $5 \mathrm{M}$ & Gypsum 10g & & FGMS-02 & FGMS-03 & & \\
\hline $\mathrm{NaOH}$ & $5 \mathrm{M}$ & Gypsum 20g & & FGMS-02a & FGMS-03a & & \\
\hline WG/ & $2 \mathrm{~N} /$ & Gypsum 10g & & $\begin{array}{l}\text { FGMSW- } \\
02\end{array}$ & FGMSW-03 & & \\
\hline $\mathrm{NaOH}$ & $5 \mathrm{M}$ & & & & & & \\
\hline $\begin{array}{l}\text { WG/ } \\
\mathrm{NaOH}\end{array}$ & $\begin{array}{l}2 \mathrm{~N} / \\
5 \mathrm{M}\end{array}$ & Gypsum 20g & $\begin{array}{l}\text { FGMSW- } \\
01 \mathrm{a}\end{array}$ & & $\begin{array}{l}\text { FGMSW- } \\
03 a\end{array}$ & & \\
\hline $\begin{array}{l}\text { WG/ } \\
\mathrm{NaOH}\end{array}$ & $\begin{array}{l}2 \mathrm{~N} / \\
10 \mathrm{M}\end{array}$ & Gypsum 20g & $\begin{array}{l}\text { FGMSW- } \\
01 \mathrm{~b}\end{array}$ & & $\begin{array}{l}\text { FGMSW- } \\
03 \mathrm{~b}\end{array}$ & $\begin{array}{l}\text { FGMSW- } \\
04 \mathrm{~b}\end{array}$ & $\begin{array}{l}\text { FGMSW- } \\
05 \mathrm{~b}\end{array}$ \\
\hline
\end{tabular}

Table 5. Infrared Characteristic Bands Identified in FA and Geopolymers Specimens 


\begin{tabular}{|ll|}
\hline Wave number $\left(\mathrm{cm}^{-1}\right)$ & Characteristic bands \\
\hline $460-550$ & plane and bending vibrations of Al-O/Si-O \\
\hline $603-618$ & Functional group of $\mathrm{AlO}_{2}$ \\
\hline $817-878-1456$ & $-\mathrm{CO}_{3}$ vibrations in $\mathrm{CaCO}_{3}$ \\
\hline 970 & Stretching vibration mode of SI-O in CSH gel \\
\hline $1420-1472$ & Si-O vibrations \\
\hline $1660-1782$ & Bending mode of H-O-H \\
\hline $2505-2519$ & $\mathrm{C}-\mathrm{O}$ vibrations in $\mathrm{CO}_{2}$ constrained in amorphous phase \\
\hline $3475-3645$ & $\mathrm{O}-\mathrm{H}$ stretching vibration of portlandite \\
\hline
\end{tabular}

\section{Figures}

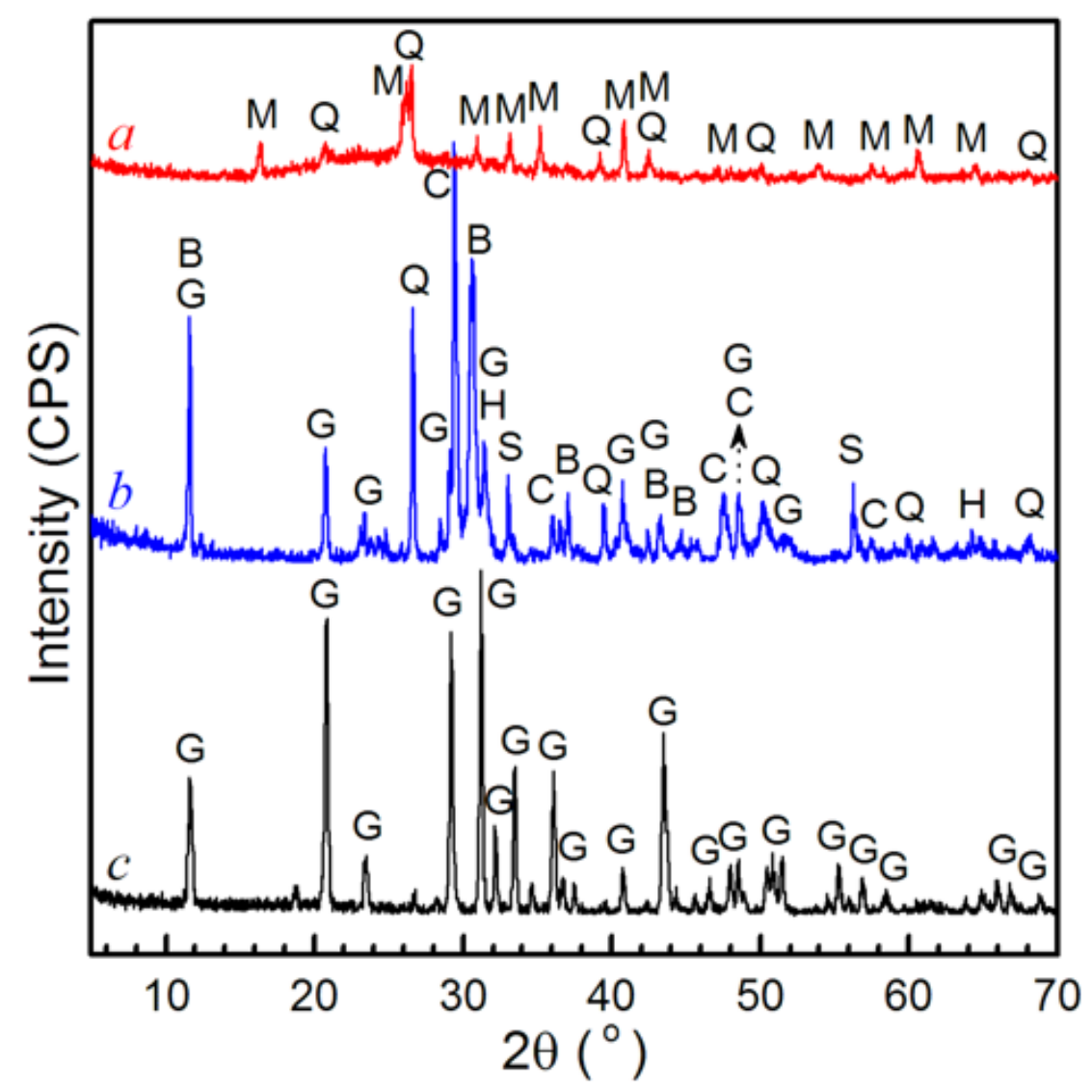

Figure 1

XRD patterns of (a) fly ash, (b) mine tailing, and (c) FGD gypsum. Note: B - Brushite (JCPDS \#09-0077), C - Calcite (JCPDS \#05-0586), G - Gypsum (JCPDS \#33-0311), H - Gehlenite (JCPDS \#35-0755), M - Mullite (JCPDS \#15-0776), Q Quartz (JCPDS \#46-1045), S - Sphalerite (JCPDS \#05-0566). 


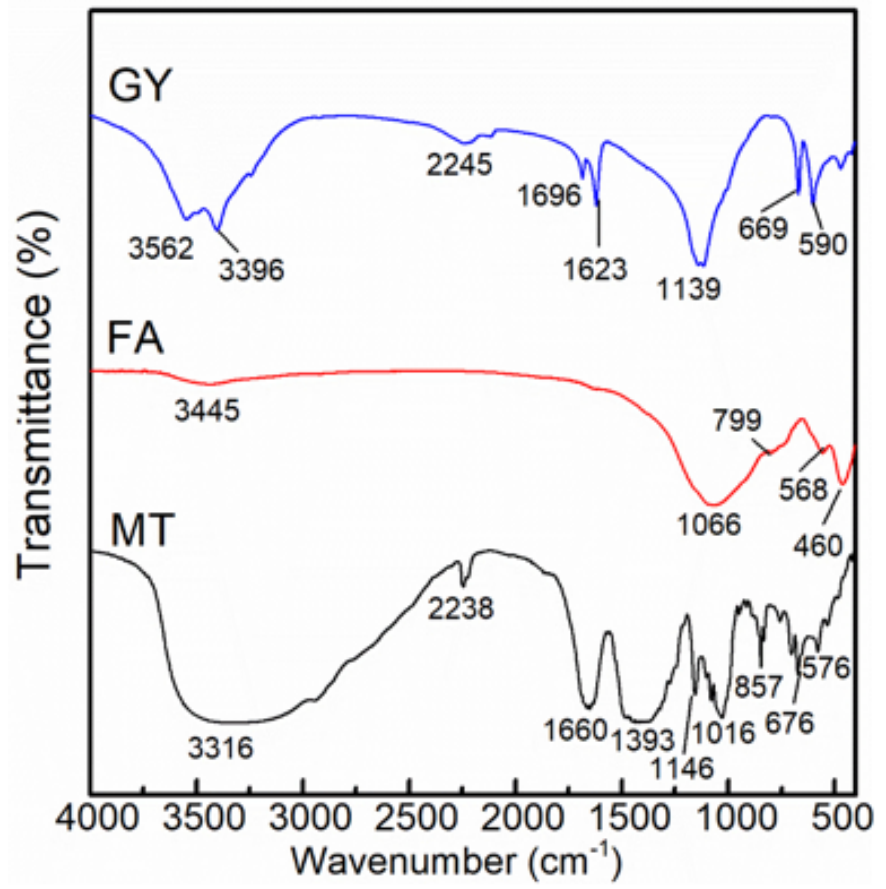

Figure 2

FTIR spectra of FA, MT and GY
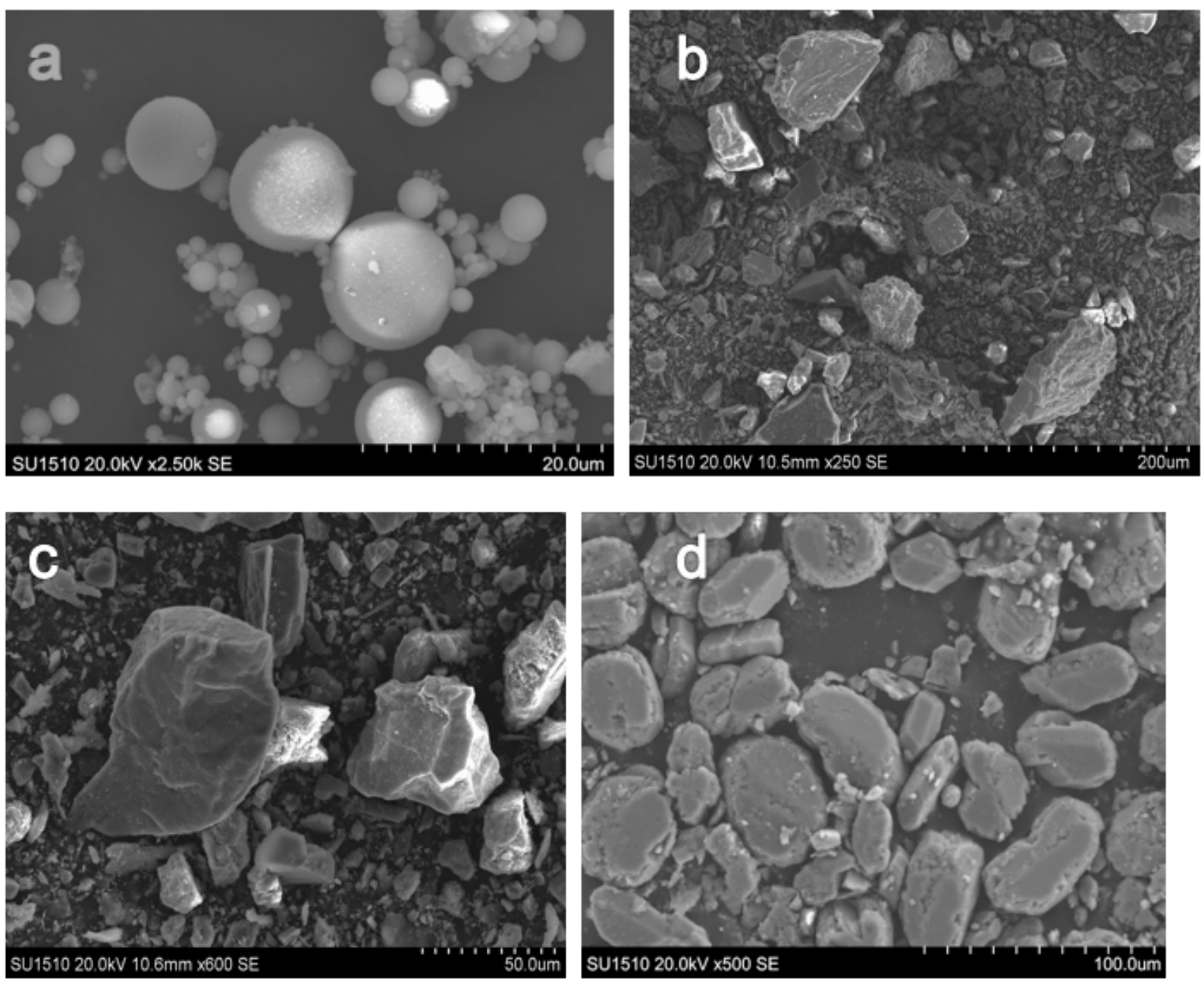

Figure 3 
SEM Images of (a) Fly Ash, (b, c) Mine Tailing, And (d) Gypsum.

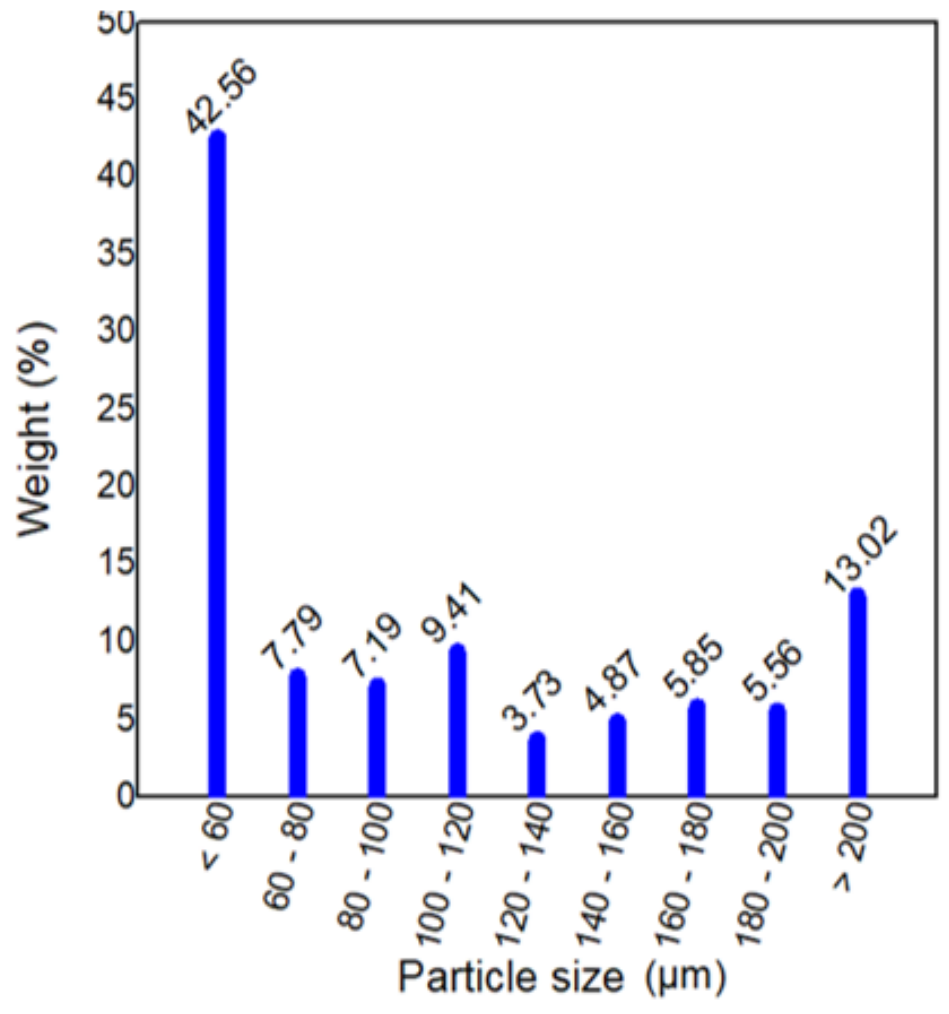

Figure 4

Particle Size Distribution of Mine tailings Note: B - Brushite (JCPDS \#09-0077), C - Calcite (JCPDS \#05-0586), G Gypsum (JCPDS \#33-0311), H - Gehlenite (JCPDS \#35-0755), M - Mullite (JCPDS \#15-0776), Q - Quartz (JCPDS \#461045), S - Sphalerite (JCPDS \#05-0566). 


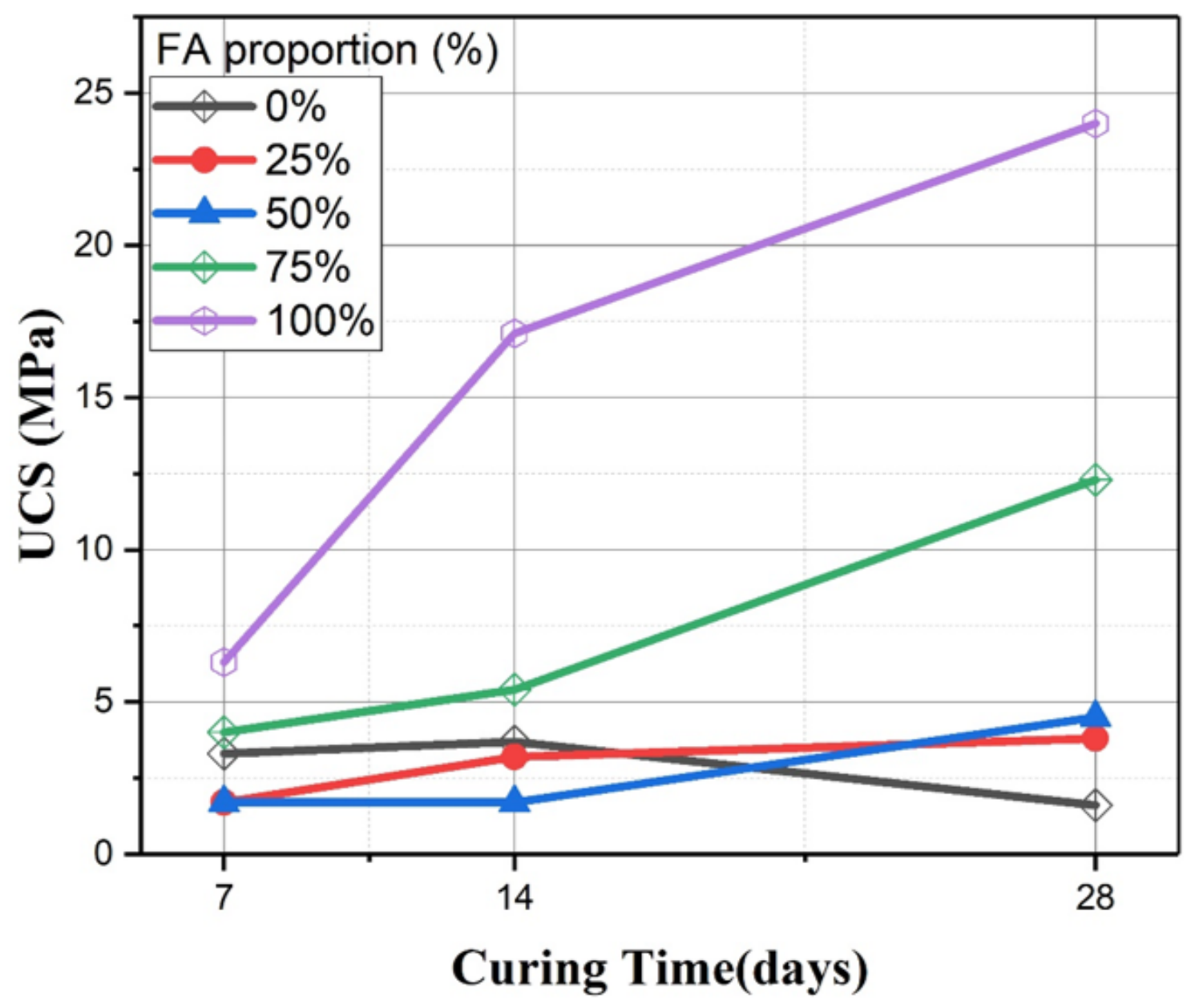

Figure 5

aging period of FMS-0xa geopolymer specimens at $10 \mathrm{M} \mathrm{NaOH}$ with different proportion of $\mathrm{FA}$ 

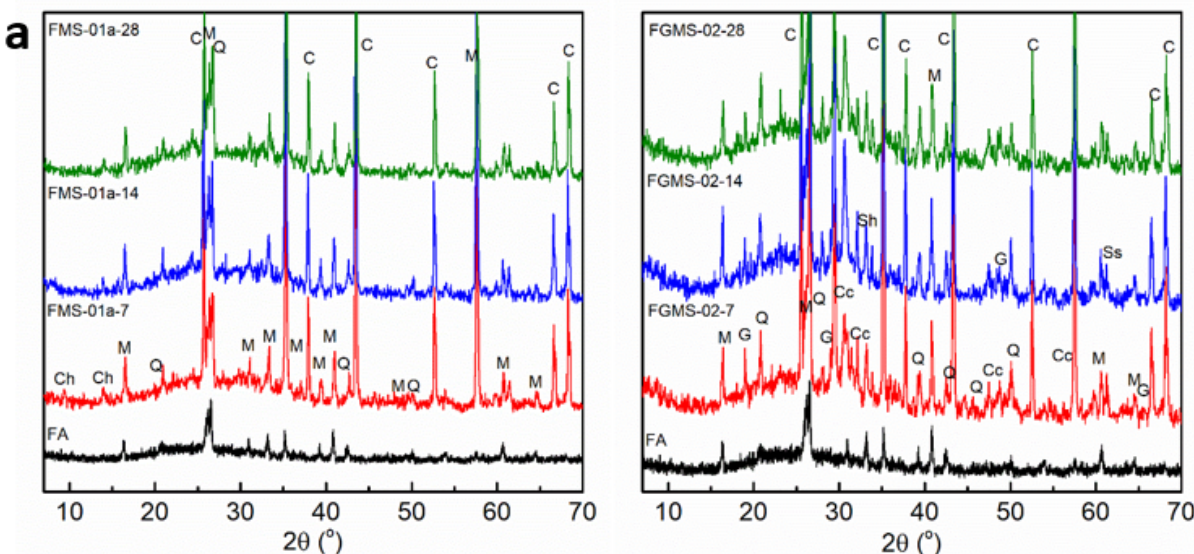

b
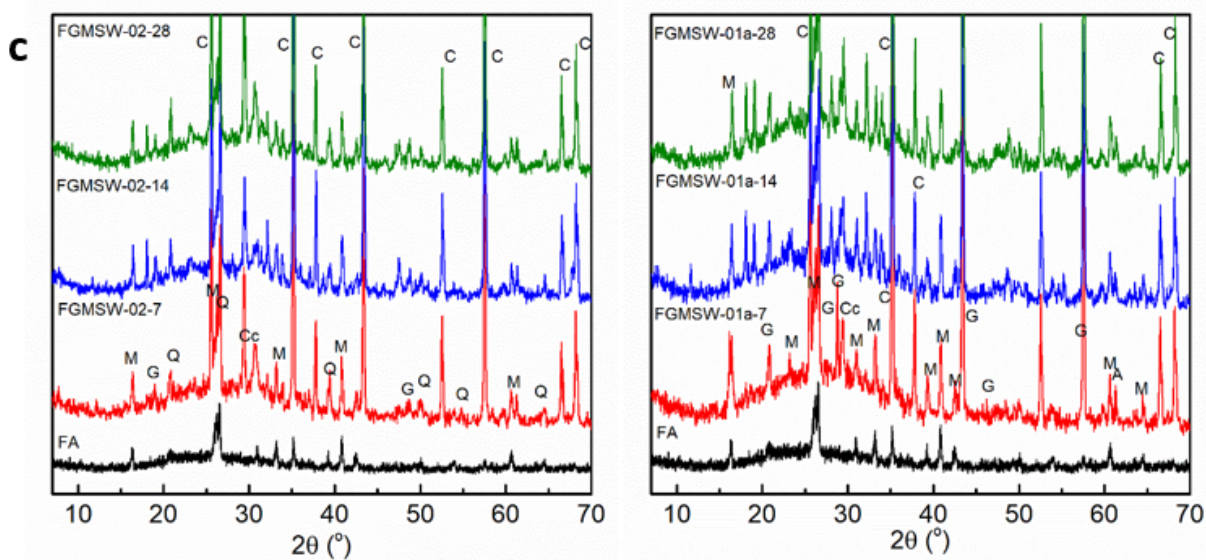

d

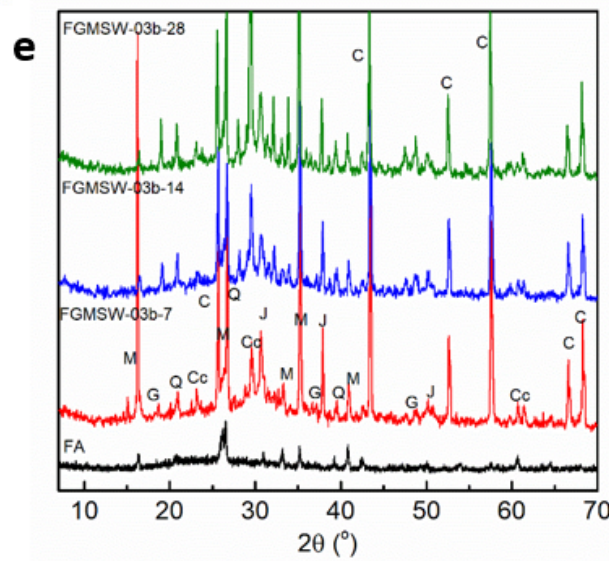

Figure 6

XRD patterns of the specimen a FMS-01a (100\% FA) b) FGMS-02 (75\% FA) c) FGMSW-02 (75\% FA), d) FGMSW-01a (100\% FA); d) FGMSW-03b (50\% FA), which described data belongs to 7, 14 and 28 days after their activation with sodium hydroxide 5M and 10M. Where $\mathrm{C}=$ Corundum Al203, $\mathrm{Cc}=$ Calcite CaCO3, G=Gypsum CaSO4 2H2O, M= Mullite Al6Si2O13, $\mathrm{Q}=$ quartz $\mathrm{SiO} 2, \mathrm{Ss}=$ Sodium silicate Na2(SiO3), Sh=Calcium Silicate hydritade Ca1.5Si0.5 xH2O, Ch= Chabazite, J= Jadeite, $A=$ Anhydrite CaSO4 

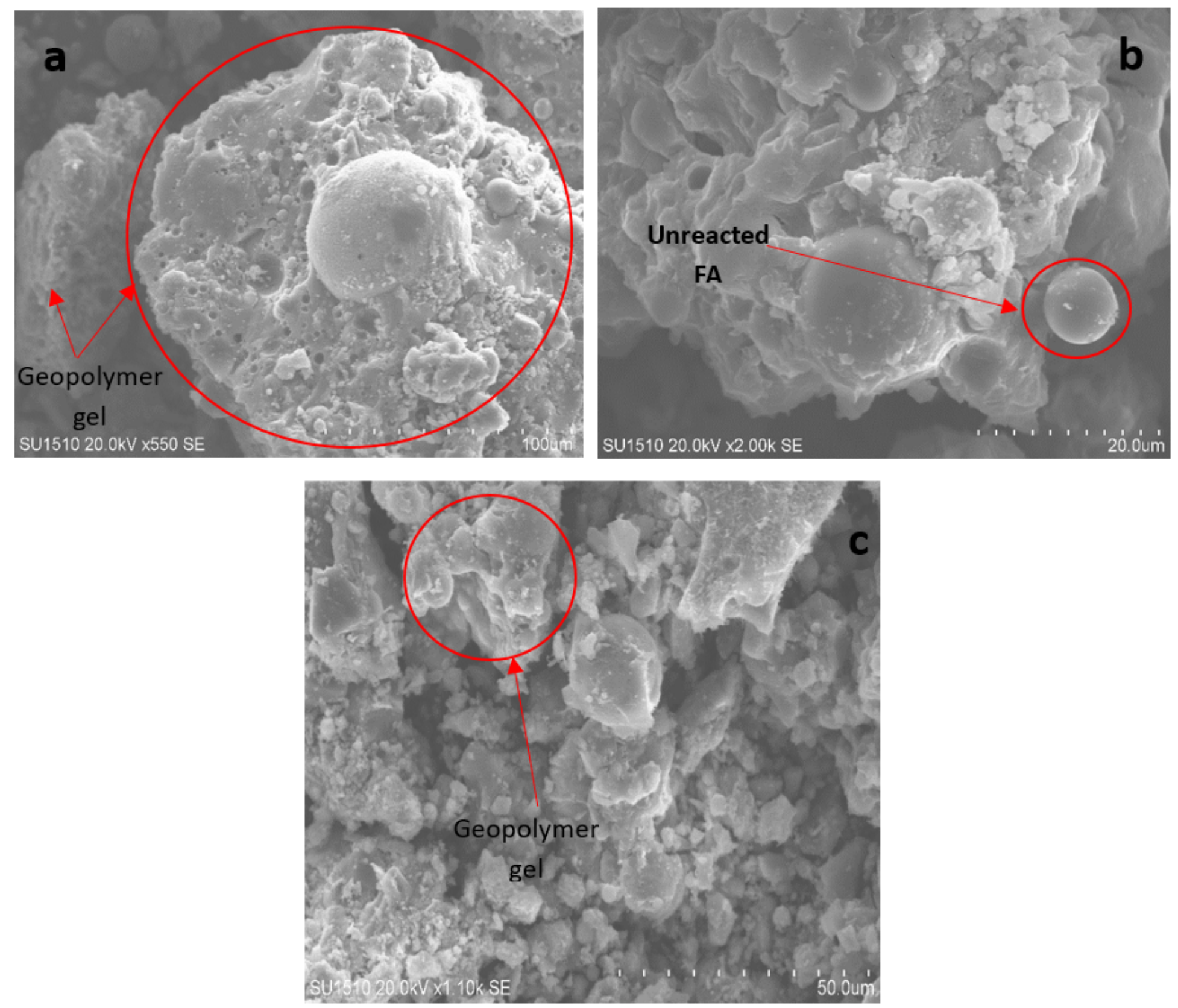

\section{Figure 7}

Scanning Electron Microscopy of geopolymer specimens (FGMSW-3b) with $100 \% \mathrm{FA}, 20 \mathrm{~g}$ of Gy at $10 \mathrm{M}$ of $\mathrm{NaOH}$ cured for: (a) 7 days, (b) 14 days and (c) 28 days curing. 

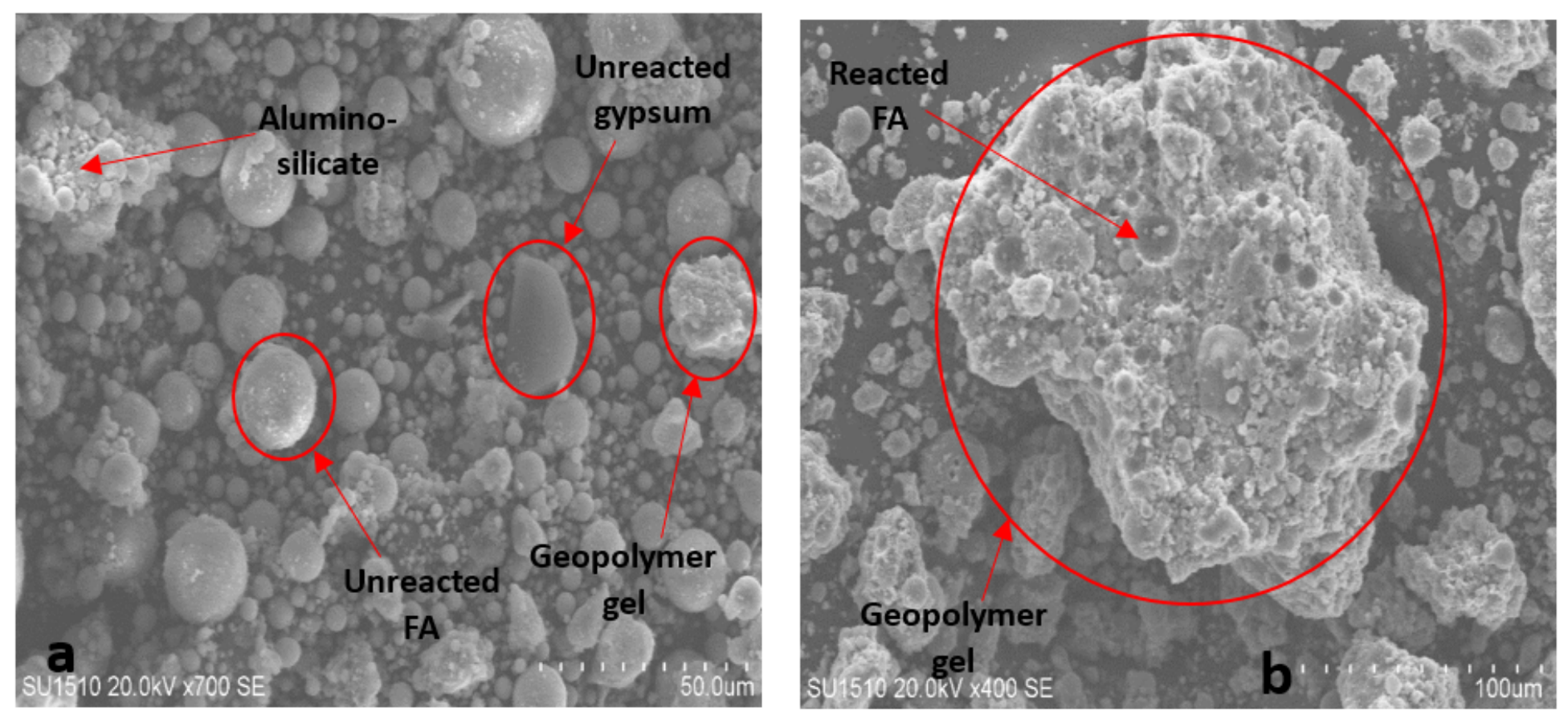

\section{Figure 8}

Scanning Electron Microscopy of geopolymer specimens (FMS-02 and FMS-02a) at the same magnification with 100\% FA at different concentration of $\mathrm{NaOH}$ (a) $5 \mathrm{M}$ and (b) $10 \mathrm{M}$ of $\mathrm{NaOH}$ cured for 14 days curing.
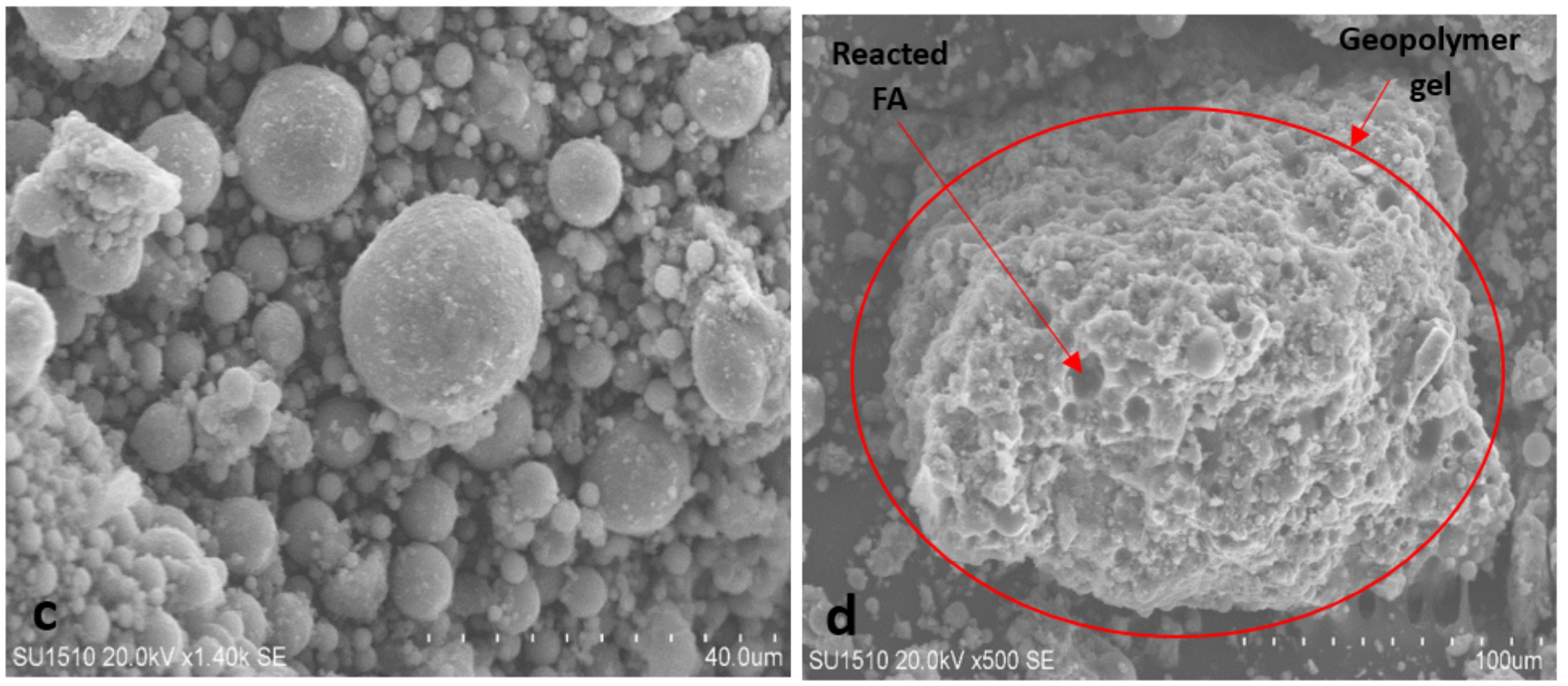

\section{Figure 9}

SEM images of geopolymer specimens (FMS-01 and FMSW-01) at low magnification with $100 \% \mathrm{FA}$ at $5 \mathrm{M}$ of $\mathrm{NaOH}$ cured for 7 days curing activated with (c) only $\mathrm{NaOH}$ and (d) both $\mathrm{NaOH}$ and Na-Silicate 

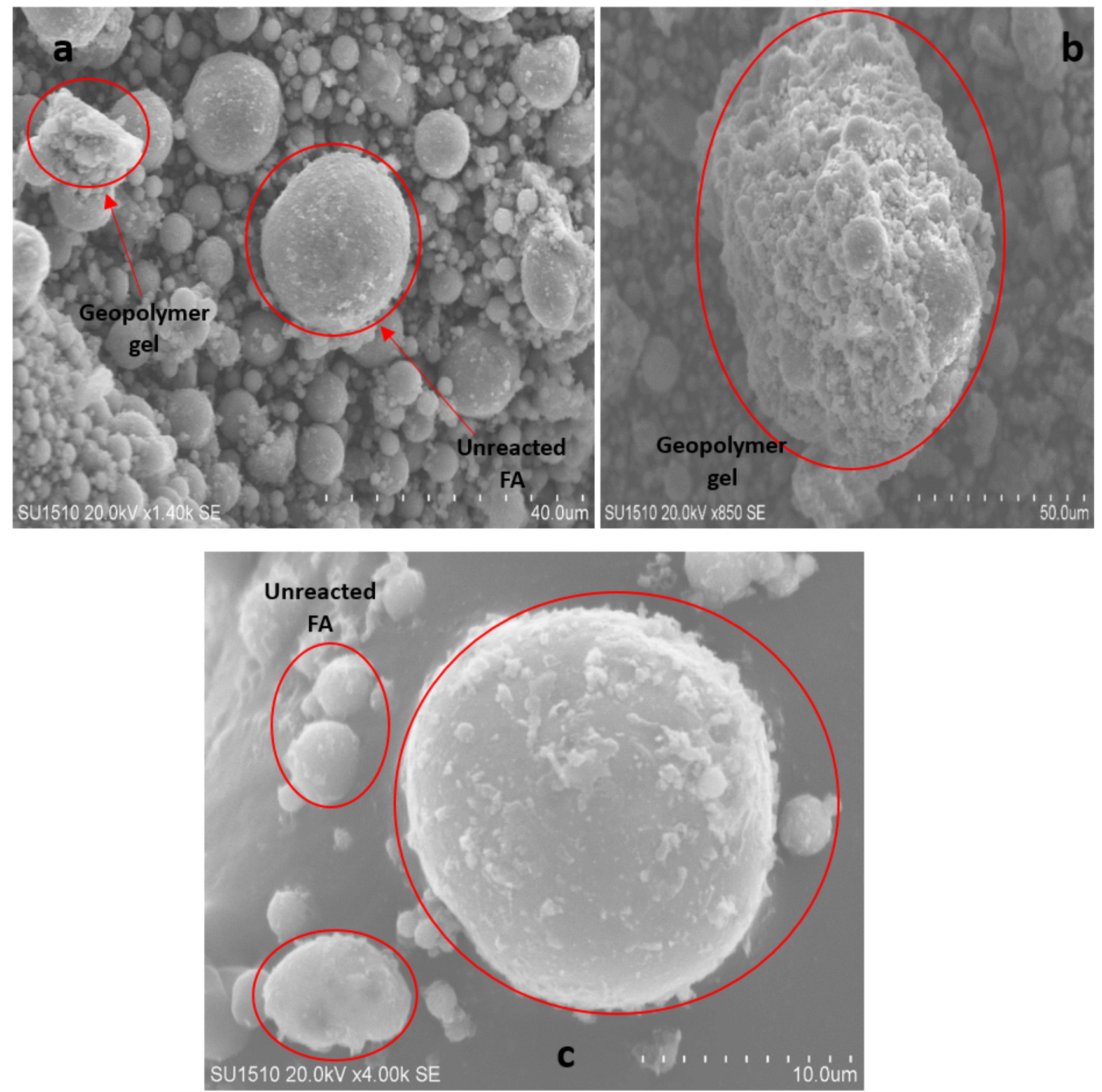

Figure 10

Scanning Electron Microscopy of geopolymer specimens (FGMS-02 and FGMS-02a) with low magnification with $75 \%$ FA at $5 \mathrm{M} \mathrm{NaOH}$ at different content of Gypsum: (a) $0 \mathrm{~g}$, (b) $10 \mathrm{~g}$ and (c) $20 \mathrm{~g}$ of Gypsum cured for 7 days curing. 

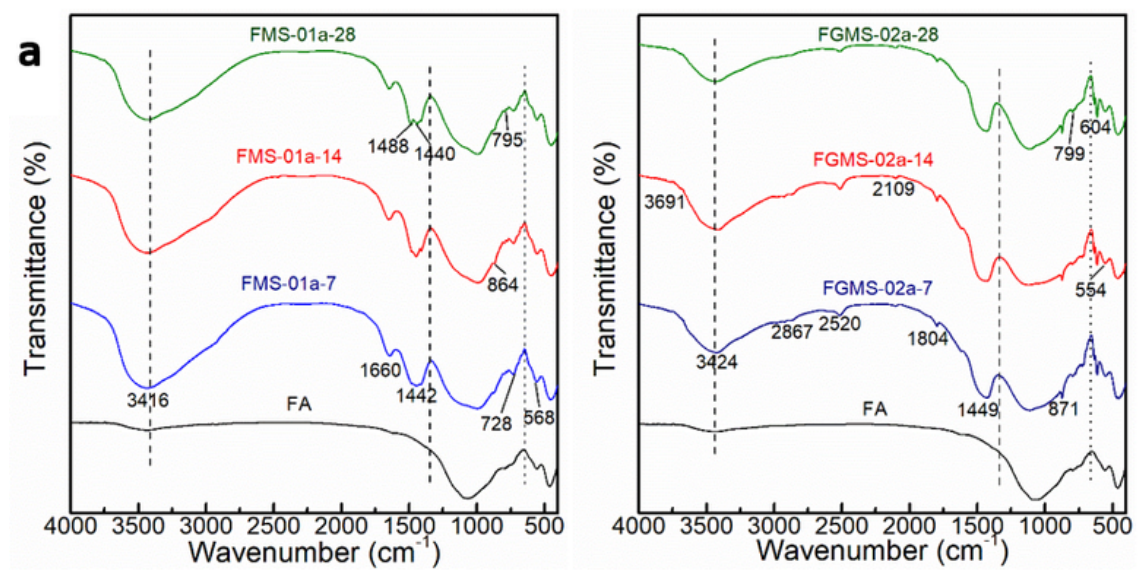

b
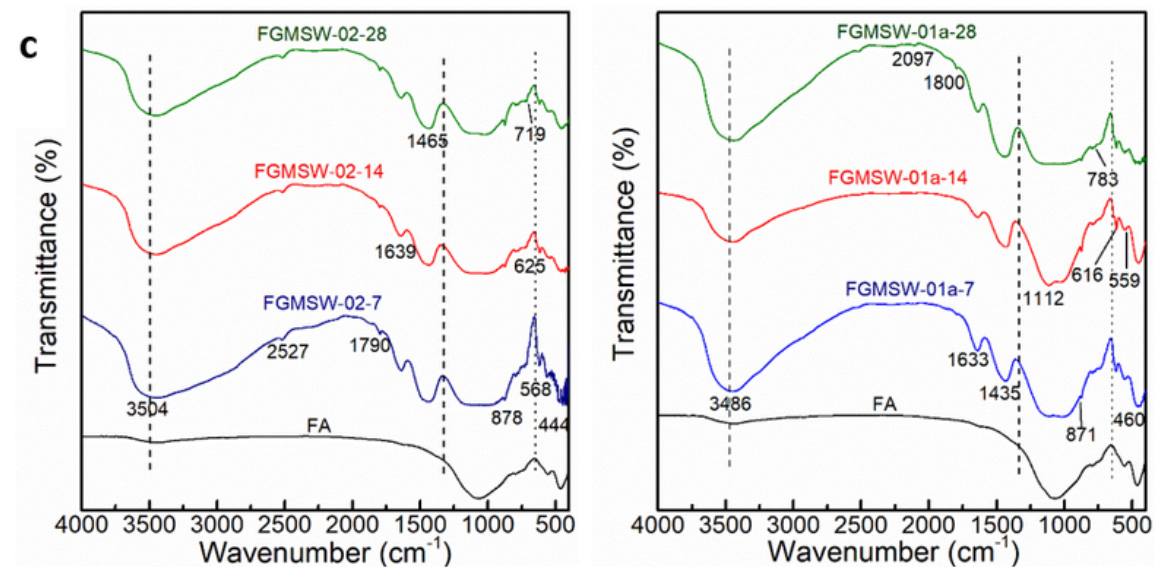

d

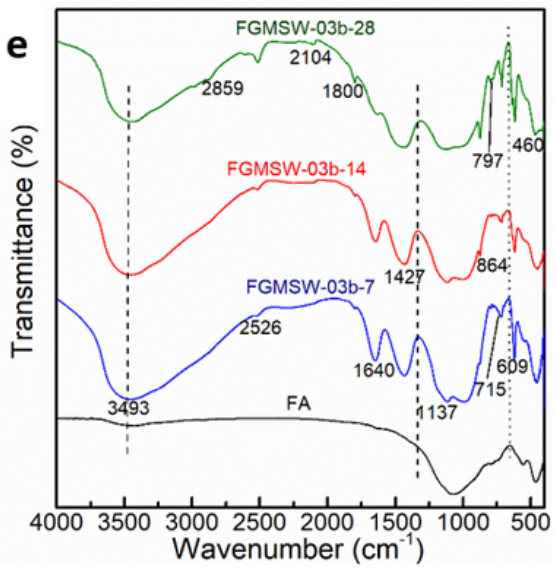

Figure 11

FTIR of the recipe after 7, 14 and 28 days, where a) FMS-01a (100\% FA), b) FGMS-02a (75\% FA), c) FGMSW-02(75\% FA), d) FGMSW-02(75\% FA), e) FGMSW-03b (50\% FA), 
a
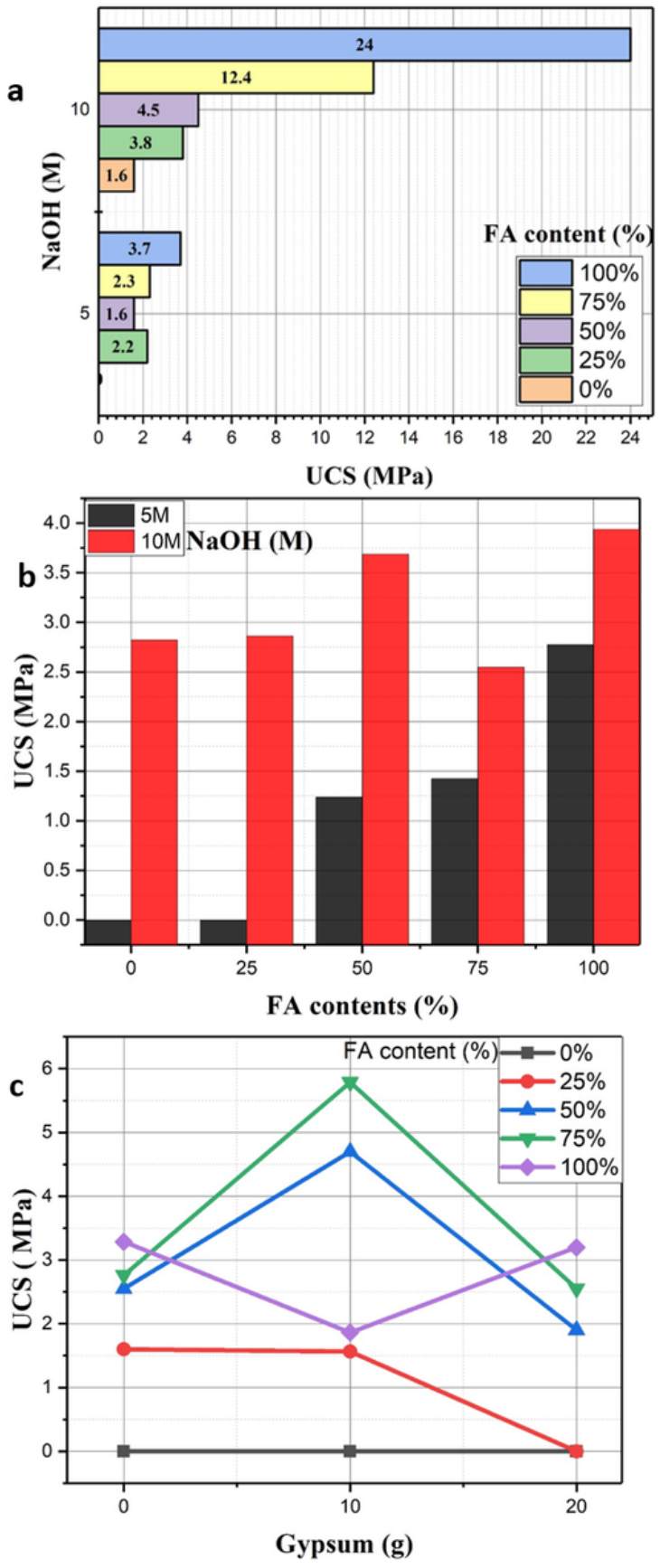

Figure 12

(a) the compressive strength with $\mathrm{NaOH}$ concentration (5 and 10M) at different proportion of $\mathrm{FA}$ and (b) compressive strength(UCS) with FA content at various $\mathrm{NaOH}$ concentration and (c) UCS vs Gypsum $(0,10$ and $20 \mathrm{~g})$ at different FA content and at $5 \mathrm{M} \mathrm{NaOH}$ cured for 7 days.

展

Figure 13

(a). Geopolymers FMS, FMSW and FMS-00a (b). Geopolymers FGMS and FGMS-00a (c). Geopolymers FGMSW, FGMSW$00 \mathrm{a}$ and FGMSW-00b 